\title{
Implementation intentions and the willful pursuit of prosocial goals in negotiations
}

\author{
Roman Trötschel ${ }^{\mathrm{a}, *}$, Peter M. Gollwitzer ${ }^{\mathrm{b}, \mathrm{c}}$ \\ ${ }^{a}$ University of Trier, FBI-Psychologie, Universität Trier, D-54286 Trier, Germany \\ ${ }^{\mathrm{b}}$ Universitaet Konstanz, Fachgruppe Psychologie, Postfach 5560, D-78434 Konstanz, Germany \\ ${ }^{\mathrm{c}}$ New York University, Psychology Department, 6 Washington Place, New York, NY 10003, USA \\ Received 23 September 2005; revised 30 May 2006 \\ Available online 8 August 2006 \\ Communicated by Fabrigar
}

\begin{abstract}
Three studies examined whether the self-regulation strategy of forming implementation intentions (i.e., if-then plans) facilitates the attainment of prosocial goals when a limited resource is to be distributed between two parties who hold adverse cognitive orientations. In three experiments, pairs of negotiators were assigned prosocial goals that either had to be supplemented with plans (if-then plans, Gollwitzer, 1999) on how to act on these goals or not. Experiment 1 used a mixed-frames negotiation paradigm in which one negotiation partner operated on a gain-frame, the other on a loss-frame. When participants had the prosocial goal to find fair agreements and furnished it with a respective ifthen plan, unfair agreements in favor of the loss-frame negotiator no longer occurred. Experiment 2 used a same-frame negotiation paradigm, where both negotiation partners had either a loss or a gain-frame. When loss-frame pairs had furnished their prosocial goals to cooperate with the negotiation partner with a respective if-then plan, reduced profits as compared to gain-frame pairs of negotiators were no longer observed. In addition, negotiators who had formed implementation intentions were more likely to use the integrative negotiation strategy of logrolling (i.e., making greater concessions on low rather than high priority issues). Experiment 3 used a computer-mediated negotiation task in order to analyze the effects of prosocial goals and respective implementation intentions on the course of the negotiation. Again, implementation intentions facilitated the pursuit of prosocial goals in the face of adversity (i.e., loss frames) by use of the integrative negotiation strategy of logrolling. The present research adds a self-regulation perspective to the research on negotiation by pointing out that the effects of negotiation goals can be enhanced by furnishing them with respective plans (i.e., implementation intentions).
\end{abstract}

(c) 2006 Elsevier Inc. All rights reserved.

Keywords: Self regulation; Negotiation; Social values; Cooperation; Cognitive barriers

\section{Introduction}

Past research on negotiations can be classified into two main lines, one adhering to a motivational and the other to

\footnotetext{
is We are very thankful to the anonymous reviewers, the members of the NYU motivation laboratory, and Henry Hammelbeck, Andrea Seifert, Christina Hausschild, and Joachim Hueffmeier who made valuable comments on an earlier version of this manuscript. The authors thank Sabine Kobs and Katrin Westphal for their help in data collection. The reported research was supported by a grant of the German Science Foundation (DFG) to the second author.

* Corresponding author.

E-mail addresses: troetschel@uni-trier.de (R. Trötschel), Peter.Gollwitzer@uni-konstanz.de, peter.gollwitzer@nyu.edu (P.M. Gollwitzer).
}

a cognitive research perspective (De Dreu \& Carnevale, 2003). The motivational perspective points to differences in concerns for one's own and the opponent's outcomes (Dual Concern Model; Pruitt \& Rubin, 1986) or to differences in social motives (e.g., prosocial vs. egoistic motives; Deutsch, 1973; De Dreu, Weingart, \& Kwon, 2000). In contrast, the cognitive research perspective focuses on information processing deficiencies and erroneous reasoning (summary by Bazerman, Curhan, Moore, \& Valley, 2000). Both perspectives have long continued to exist without referring to each other. Recently, De Dreu and Carnevale (2003) suggested a "motivated information processing perspective" to redress the one-sided perspective of either an isolated motivational 
or cognitive approach. In addition, the authors call for integrating findings from other areas of psychology (e.g., emotional processes). Following this suggestion, the present research tries to add a self-regulation (volition) perspective (Gollwitzer, 1990, 1996, 1999). More specifically, it is analyzed whether people who face strong cognitive barriers arising from loss frames (Kahneman, 1992) attain their prosocial negotiation goals more effectively if the willful selfregulation strategy of planning out goal implementation in advance is used.

\section{Cognitive barriers and loss frames in negotiations}

The cognitive perspective in negotiation research focuses on information processing deficiencies and erroneous reasoning. A very prominent cognitive barrier in negotiations arises from different cognitive framing of potential negotiation outcomes. According to Kahneman and Tversky's (1979) prospect theory, it is crucial whether negotiators conceptualize the potential negotiation outcomes in terms of either gains or losses (Bazerman, Magliozzi, \& Neale, 1985; Kahneman, 1992). Negotiators with a gain-frame use a reference point below their prospective outcomes, whereas negotiators with a loss-frame use a reference point above their prospective outcomes. Negotiation experiments that manipulate gain or loss frames have repeatedly shown that attained profits are influenced by such outcome framing. Negotiators provided with a high reference point (which induces a loss-frame) commonly concede less, use more contentious tactics, hold higher limits, take longer to reach settlements, and are less likely to settle a dispute than those supplied with a low reference point (which induces a gain-frame; summary by De Dreu, Carnevale, Emans, \& Van de Vliert, 1995). In sum, several studies on framing effects in negotiations (Bazerman et al., 1985; Bottom \& Studt, 1993; Olekalns, 1994) suggest that gain versus loss frames have a strong impact on negotiation outcomes, as loss frames lead to comparatively unfair outcomes and hinder the finding of integrative solutions.

Framing effects on achieved negotiation outcomes have been explained by the resistance hypothesis which states that participants with a loss-frame are less willing to make concessions than participants with a gain-frame (an alternative explanation in terms of risk seeking is provided by Bazerman et al., 1985). According to Kahneman (1992) loosing some value or commodity is experienced as more painful than not gaining a value or commodity of equal value. Thus, it is assumed that framing negotiation outcomes in terms of losses rather than gains induces a comparatively stronger resistance to concession making, which in turn produces suboptimal agreements.

\section{Motivation in negotiations}

A very prominent motivational approach to the analysis of negotiation behavior is suggested by the Cooperation Theory (De Dreu \& Weingart et al., 2000; Deutsch, 1973;
Giebels, De Dreu, \& Van de Vliert, 2000; see also Messick $\&$ McClintock, 1968) which deals with differences in people's social motives or social value orientations. Negotiators with an egoistic motive try to maximize their own outcomes with no (or negative) regard for their opponents' outcomes. In contrast, negotiators with a prosocial motive try to maximize both their own and their opponents' outcomes. Prosocial and egoistic motives do not only affect actual behavior but also its interpretation by negotiators. Weingart, Bennett, and Brett (1993) observed that negotiators with instructions promoting a prosocial motive (orientation) engaged more often in problem solving behaviors and realized integrative potentials to a greater extent than negotiators with instructions promoting an egoistic motive (orientation). Negotiators with a prosocial motive are more willing to concede, have less ambitious aspirations, seek and process information that allows them to collaborate effectively, use lower demands, focus more on fair agreements, are more willing to exchange information, use less distributive (e.g., threatening) negotiation behavior, achieve higher joint outcomes, and engage less in rigid black-andwhite thinking than negotiators with an egoistic motive (summary by De Dreu \& Weingart et al., 2000).

A further motivational approach to the analysis of negotiation behavior is suggested by the Dual Concern Model (Pruitt \& Carnevale, 1993; Pruitt \& Rubin, 1986) which postulates two kinds of concerns, other-concerns and self-concerns, each ranging in strength from weak to strong. The Dual Concern Model predicts problem solving to occur if negotiators have a high level of prosocial orientation (i.e., high other-concern) and a high resistance to concession making (i.e., high level of self-concern). In line with this assumption, De Dreu and Weingart et al. (2000) report in their metaanalysis that negotiators with prosocial motives and a resistance to concession making are most likely to engage in problem solving and to achieve higher joint outcomes.

\section{Overcoming loss-frame effects by social motives}

Barriers arising from cognitive loss frames should be successfully overcome by negotiators with a high otherconcern in terms of a prosocial orientation (De Dreu et al., 1995). Indeed, four experiments analyzed the influence of social motives and cognitive framing effects on negotiation outcomes. These experiments used monetary incentives to induce social motives, whereas gain and loss frames were manipulated by pay-off charts that framed potential outcomes either in terms of profits or expenses, respectively. However, the reported experiments revealed inconsistent results on the effect of prosocial motives with loss-frame pairs of negotiators. In a first experiment by Olekalns (1994), pairs of loss-frame negotiators with a prosocial motive arrived at agreements of lower joint profits than gain-frame pairs of negotiators. In contrast, Carnevale, De Dreu, Rand, Keenan, and Gentile (1994, cited in De Dreu et al. 1995) report that loss-frame pairs of negotiators with a prosocial motive were even more likely to detect 
integrative agreements than gain-frame negotiators with a prosocial motive. Finally, in two recent studies by Olekalns (1997) same-frame pairs of negotiators were unable to overcome the cognitive barrier of a loss-frame unless the negotiation situation contained an element of cooperation (e.g., a cooperative negotiation partner).

Olekalns $(1994,1997)$ also analyzed whether mixedframe pairs of negotiators with prosocial motives in a distributive (nonintegrative) negotiation setting will differ in their level of individual profits. As it turned out, within mixed-frame pairs of negotiators the loss-frame negotiators exploited their gain-frame negotiation partner, and this was particularly true in pairs of negotiators with a prosocial instruction set (Olekalns, 1997; Study 1 and Study 2). These findings by Olekalns are in contrast to previous findings indicating that negotiators with a prosocial value orientation use prosocial heuristics like "equal split is fair" or "share and share alike" (De Dreu \& Boles, 1998) and generally exhibit a higher concern for equal outcomes (De Dreu \& Van Lange, 1995). In addition, recent research on prosocial value orientations in social dilemmas indicates that participants with a prosocial value orientation not only try to pursue high joint outcomes but also much equality in outcomes (De Cremer \& Van Lange, 2001; Van Lange, 1999). Apparently, in the studies by Olekalns, loss-frame negotiators were not able to overcome the cognitive lossframe barrier via their prosocial orientation but instead took advantage of the prosocial orientation of their gainframe negotiation partners.

\section{Goal intentions versus implementation intentions}

Research on motivation has traditionally used the concepts of need, motives, incentive, and expectations to arrive at predictions of what kind of behaviors people will perform. Over the last two decades, however, the concept of goals and intentions has become increasingly more important (Gollwitzer \& Moskowitz, 1996). More recently, Gollwitzer $(1993,1999)$ introduced the self-regulation strategy of if-then planning (i.e., forming implementation intentions) in the context of making a distinction between two forms of intentions, one relating to goals and the other to plans. Goal intentions specify a desired end point and take the format of "I intend to reach $\mathrm{x}$ !", whereby the $\mathrm{x}$ can be a behavior or an outcome. The strength of the goal intention (determined by the person's commitment to realize the goal) produces a certain behavioral orientation geared at initiating the intended behavior or realizing the desired outcome. In contrast to goal intentions, implementation intentions specify a plan on the when, where, and how of acting on one's goal intentions. Implementation intentions are subordinate to goal intentions and have the format of "If situation $\mathrm{x}$ arises, then I will perform goal-directed behavior $y$ !", thus linking an anticipated opportunity to a select goal-directed response. By forming implementation intentions, people plan out in advance (i.e., pre-select) which situations and behaviors they intend to use to achieve their goals (goal intentions). Implementation intentions are not to be confused with concrete goal intentions, however, as implementation intentions by adhering to an if-then format are structurally different from goal intentions (see Oettingen, Hönig, \& Gollwitzer, 2000). Moreover, goal intentions do not create behavioral orientations such as those stemming from incentive manipulations or value orientations as goal intentions are based on a decision (i.e., an act of committing oneself) to initiate a certain behavior or reach a desired outcome.

In numerous studies (meta-analysis by Gollwitzer \& Sheeran, 2006) it has been shown that implementation intentions facilitate action initiation by making it more swift (e.g., Gollwitzer \& Brandstätter, 1997), efficient (e.g., Brandstätter, Lengfelder, \& Gollwitzer, 2001), and independent of conscious intent (Bayer, Moskowitz, \& Gollwitzer, 2003). More recent research (summarized by Gollwitzer, Bayer, \& McCulloch, 2005) has focused on using implementation intentions to prevent an ongoing goal pursuit from getting derailed by unwanted negative influences that may originate both from inside (e.g., detrimental self-states such as being irritated or angry when the goal is to be nice to a certain person) and outside (e.g., adverse situational conditions such as a lack of accountability in an achievement situation). There are two major strategies in which implementation intentions can be used to control such negative influences on one's ongoing goal pursuit and prevent unwanted derailing. The first strategy is forming suppression-oriented implementation intentions that focus on reducing the intensity of the derailing responses elicited by internal or external distractive stimuli (Gollwitzer \& Schaal, 1998; Mischel, Cantor, \& Feldmann, 1996). Such suppression-related implementation intentions specify the critical stimuli in the if-part and link it to an attempt at suppressing related unwanted responses in the then-part of the implementation intention. The second viable strategy does not gear implementation intentions towards anticipated critical stimuli, but instead focuses on spelling out the ongoing goal pursuit at hand. It is this second strategy that is scrutinized in the present set of studies. More specifically, we analyzed whether forming implementation intentions that spell out how to act on the goal to behave in a prosocial manner in an upcoming negotiation, manages to protect this goal pursuit from the potentially derailing influences of framing the negotiation outcomes in terms of losses.

\section{The present research}

Previous research on framing effects in negotiations indicates that loss-frame negotiators experience an increased resistance to concession making, which in turn may lead them to oversee the necessity to cooperate with their counterpart. One strategy to overcome this impediment arising from cognitive loss frames can be found in the motivational research tradition on negotiations: negotiators with a prosocial motivation are more likely to regard their 
counterparts' interests in order to find fair and integrative negotiation outcomes. However, as mentioned before, research on the effect on prosocial motives in loss-frame negotiation settings reveal an inconsistent picture (De Dreu, Carnevale, Emans, \& Van de Vliert, 1994, 1995; Olekalns, 1994, 1997).

Negotiation research within the motivation tradition has so far mainly focused on social motives, but has not yet explored whether willful self-regulation strategies such as forming implementation intentions succeed in strengthening the positive effects of prosocial goal intentions. Fairness goals as well as cooperation goals can be seen as valid operationalizations of a prosocial orientation, as persons with a prosocial motive commonly strive for fair outcomes and pursue cooperative interactions with their negotiation partners (De Cremer \& Van Lange, 2001; De Dreu \& Boles, 1998; De Dreu \& Van Lange, 1995; Van Lange, 1999).

The present research tries to integrate research on selfregulation (e.g., self-regulation by forming implementation intentions, Gollwitzer, 1999) with negotiation research. This approach corresponds to the claim made by De Dreu and Carnevale (2003) that next to established cognitive and motivational research traditions, findings of other areas of psychology need to be considered to achieve a comprehensive understanding of the psychological processes underlying negotiations. Based on previous research on implementation intentions, we assume that controlling one's negotiation behavior via the self-regulation strategy of forming if-then plans should be a powerful tool for negotiators to implement prosocial negotiation goals even in the face of adversity (e.g., loss-frame negotiation contexts). More specifically, we hypothesize that implementation intentions shield the pursuit of prosocial goals from the negative influences of loss framing (shielding hypothesis).

From the perspective of the self-regulation research tradition, negotiations particularly lend themselves well to investigate the power of implementation intentions: negotiations are cognitively very demanding tasks in which a large amount of information has to be processed on-line and the course of events is hard to predict. Thus, negotiations can be understood as the prototype of a complex situation in which the pursuit of desired goals can easily become derailed. Therefore, analyzing whether the beneficial effects of implementation intentions found in previous research also hold true in negotiations is of great interest to the research on self-regulation.

In the present research, we expected that the self-regulation strategy of forming implementation intentions facilitates the pursuit of prosocial negotiation goals even in the face of adversity (shielding hypothesis). In all three experiments, we expected that a loss-frame negotiation context should increase negotiators' resistance to concession making, which in turn reduces the chance to find fair and integrative negotiation outcomes. In line with the motivation research tradition, we expected that prosocial goals would only reduce the negative impact of a loss-frame negotiation context, whereas complete abolishment of this negative impact should only be observed if prosocial goals are furnished with respective implementation intentions (Gollwitzer, 1999). In our first experiment, we assigned the specific prosocial goal of being fair in terms of achieving equal outcomes in a same-preferences negotiation context. In the second and third experiment, we assigned the specific prosocial goal of being cooperative in a different-preferences negotiation context. Furthermore, in Experiment 3 we used a computer-mediated negotiation task in order to analyze how prosocial goals and respective implementation intentions unfold their effects in the course of negotiation.

\section{Study 1: Control of loss-frame effects in mixed-frame pairs of negotiators}

In our first experiment, pairs of negotiators were assigned the role of representatives of two neighboring countries (i.e., the blue and the orange nations) and asked to negotiate the distribution of a disputed island (i.e., its regions, villages, and towns). Before explaining the negotiation task in detail, the participants in the prosocial goal intention condition were asked to adopt the goal of achieving a fair negotiation outcome. In the implementation intention condition, negotiators were instructed in addition to furnish this goal with a respective implementation intention. Finally, the control group participants did not receive any instructions to set themselves such a goal or make respective plans. In previous research (reviewed by De Dreu \& Weingart et al., 2000), prosocial motivation was commonly contrasted with egoistic motivation. However, as our hypothesis makes the specific claim that prosocial goals furnished with respective implementation intentions (as compared to mere prosocial goals) are more helpful to ameliorate the negative effects of the resistance to concession making associated with a cognitive loss-frame, the present three-groups design is targeted at prosocial goals only.

Several experiments indicate that loss-frame negotiators outperform their gain-frame counterparts in mixed-frame negotiations (i.e., a gain-frame negotiator meets a lossframe counterpart), resulting in unfair negotiation outcomes (Bottom \& Studt, 1993; Olekalns \& Frey, 1994; Olekalns, 1994, 1997). Olekalns (1997) reports that this is even true when a prosocial orientation is induced via monetary incentives. In line with these results, distributive justice studies show that loss-frame participants are less concerned with just outcomes but rather with minimizing their losses, irrespective of the quality of the social relationship with their counterparts (De Dreu, 1996). As perceived injustice burdens social relationships (Pillutla \& Murnighan, 1996), leads to conflict escalation, and self-defeating retaliation (Guth, Schmittberger, \& Schwarze, 1982), it seemed important to us to test whether the self-regulatory strategy of furnishing prosocial goals (i.e., fairness goals) with respective implementation intentions helps to overcome the cognitive barriers associated with mixed-frame pairs of negotiators.

In the present experiment, we induced a mixed-frame negotiation context in which one negotiator acted on a 
gain-frame whereas the other negotiator acted on a lossframe. We predicted that pairs of negotiators in the three experimental conditions should differ in the degree of fairness of their negotiation outcomes, as indicated by the differences in individual profits achieved. As negotiators acting on a loss-frame are expected to reveal a higher resistance to concession making than their gain-frame negotiation partners, unfair agreements in favor of the loss-frame negotiators should be observed in the control group. In the mere fairness goal condition, resistance to concession making should get into conflict with the assigned fairness goal and the degree of unfairness in profits should be reduced. Finally, in the fairness goal plus implementation intention condition, the participants' negotiation behavior should be controlled by their if-then plans, and thus the resistance to concession making induced in the loss-frame negotiators should be blocked from unfolding its negative influence on the negotiation outcome. Accordingly, implementation intention participants should manage to arrive at equality in negotiation outcomes.

\section{Method}

\section{Participants}

Ninety male students at the University of Konstanz, Germany, with different academic majors (e.g., law, education, business, and philosophy), aged between 19 and 29 years (the median age was 24) participated in this study. All participants received $5 €$ (approximately $\$ 5$ ) for remuneration. Participants were recruited through leaflets and randomly put together to pairs of negotiators.

\section{Design}

The present study follows a 2 within (cognitive frame: gain, loss) $\times 3$ between (goal condition: control, goal intention, implementation intention) factorial design.

\section{Procedure and materials}

Within each negotiation pair, participants were randomly assigned to play the role of one or the other representative of two neighboring countries (blue nation vs. orange nation) disputing over an island, said to be close to the main land of both countries. The negotiators took their seats opposite to each other at a table on which a map was depicting the island with its different kinds of landscapes. The island consisted of 25 different regions (i.e., 5 cornfields, 6 forests, 7 pastures, and 7 mountain regions) with 5 villages and 3 towns on part of the regions.

The three experimental conditions were established as follows. Participants of the mere goal intention condition were instructed to set themselves the following goal for the upcoming negotiation: "I want to find a fair solution!", whereas participants in the goal plus implementation intention condition were assigned this fairness goal and in addition instructed to adopt the following plan on how to implement this goal: "And if I receive a proposal on how to share the island, then I will make a fair counterproposal!".
We specified the receiving of a proposal as the critical cue in the if-part of the implementation intention, as this situation can be assumed to arise reliably in the upcoming negotiation. Participants of the control condition did not receive any such goal or plan instructions.

In this first experiment, we used a same-preferences negotiation task (i.e., both negotiation parties had the same-preferences towards the given negotiation issues of villages, towns, and regions). All participants were informed about their preferences towards the various regions, villages, and towns by pay-off charts. For the lossframe participants, these charts expressed the values of the regions, villages, and towns in terms of losses (negative value points); for the gain-frame participants these values were expressed in terms of gains (positive value points). Thus, loss-frame participants received an issue chart that listed the different kinds of regions with a corresponding negative number, indicating the losses associated with giving away a certain region, village, or town. These losses were put in reference to the total value of the whole island (96 points). Gain-frame participants were shown an issue chart with positive values, indicating the gains associated with receiving a certain region, village, or town. The absolute values points for the different regions, villages, and towns, however, stayed the same on the loss-frame versus gain-frame issue charts. The cornfields represented a value of 5 points each, the forests a value of 3 points each, the pastures a value of 2 points each, and the mountain regions a value of 1 point each. Finally, the villages had the value of 2 points each and the towns were worth 4 points each.

To make fairness an important issue, participants were informed that this was the first negotiation in a whole series of subsequent negotiations. The uneven number of cornfields, pastures, and mountain regions as well as the added villages and towns located within some of the regions, made it quite challenging to find a fair agreement in terms of equal individual profit points. At the outset of the negotiation, all regions were marked by the loss-frame negotiator's flag (framing and color of nation were counterbalanced). Both negotiators were told that they both had equal rights to acquire the regions on the island and that they had to agree on the ownership of the different regions, villages, and towns by leaving the loss-frame participant's flag on the region or removing and replacing it with the flag of the gain-frame participant. Throughout the experiment both negotiation partners monitored the negotiation by marking regions taken into possession on a separate sheet of paper. Regions that were not marked on the sheet of paper after the negotiation was ended were treated as "no man's land". Consequently, the loss-frame participants had to remove their flags from these nondistributed regions at the end of the negotiation, and the points for losing these regions were subtracted from the total value of the island (96 points). This was done to clarify that as long as negotiators did not agree on the ownership of the given negotiation issues, they were not to gain (gain-frame negotiators) or lose (loss-frame negotiators) points for issues where they failed to arrange ownership. 
Finally, participants were asked to not compare their payoff charts. The negotiation was said to be limited to $15 \mathrm{~min}$, and a beep presented $2 \mathrm{~min}$ prior to the end of negotiation warned participants that the negotiation was about to end. Participants were left alone during the negotiation. The female experimenter returned after $15 \mathrm{~min}$ to end the negotiation. She then handed out a questionnaire that checked on whether the gain-frame versus loss-frame manipulation had produced a stable cognitive loss or gain orientation ("How important is it for you to minimize losses and to maximize gains?" 9-point answer scale ranging from $-4=$ minimize losses to $+4=$ maximize gains). The questionnaire also inquired about participants' commitment to the assigned prosocial goal ("How committed do you feel to the goal to find a fair solution?"); the commitment item with respect to the suggested implementation intention read: "How committed do you feel to the plan: If I receive a proposal on how to share the island, then I will make a fair counterproposal!". These items were accompanied by 10-point scales, ranging from 0 (not at all) to 9 (very). When participants had completed this final questionnaire they were thoroughly debriefed, thanked, and paid for participation.

\section{Results}

The statistical analyses performed on the manipulation check variable and the negotiation outcome variable used the degrees of freedom related to the number of pairs involved (and not the degrees of freedom related to the number of participants). This conservative approach accounts for the fact that the individual scores within each pair cannot be considered to be independent from each other.

\section{Manipulation checks}

The two-factorial ANOVA on outcome focus (maximizing gains versus minimizing losses) revealed a significant main effect for the within factor cognitive frame, $F(1,42)=11.67, \quad p<.001$. Gain-frame participants $(M=1.16, S D=1.78)$ reported a higher importance of maximizing gains compared to minimizing losses than lossframe participants $(M=-.40, S D=2.19)$. The main effect of cognitive frame on outcome focus was not qualified by an interaction with the between factor of goal condition, $F_{\text {S }}>1.0$, indicating that in the three goal conditions (goal intention, implementation intention, control) the cognitive frame manipulation was equally effective.

The two-factorial ANOVA on commitment towards the assigned goal intention revealed a marginally significant main effect for the between factor goal condition, $F(2,42)=2.70, p=.07$, that was not qualified by an interaction with the cognitive-frame factor, $F<1.0$. Participants in the two goal conditions (i.e., the mere goal intention condition and the goal intention plus implementation intention condition) reported a higher goal commitment $(M=6.91$, $S D=2.16)$ than control participants $(M=5.53, S D=2.13)$, who did not have the goal to be fair, $t(43)=2.35, p<.05$; the mere goal intention condition, however, did not differ from the goal intention plus implementation intention condition, $t<1.0$. This pattern of results indicates that adopting the suggested implementation intention did not increase participants' commitment to the respective superordinate goal intention, a finding that is common to implementation intention research (summary by Gollwitzer \& Sheeran, 2006). Accordingly, any differences in attaining the goal of reaching a fair negotiation outcome between goal intention and implementation intention participants (see below) cannot be interpreted in terms of differences in goal commitment.

The two-factorial ANOVA on the commitment towards the assigned implementation intention revealed a significant main effect for the between factor goal condition, $F(2,42)=6.44, p<.01$, that again was not qualified by an interaction with the cognitive-frame factor, $F<1.0$. As expected, participants in the implementation intention condition $(M=7.03, S D=1.64)$ reported a higher commitment to the assigned plan than participants in the two other conditions $(M=5.40, S D=1.81), t(43)=2.93, p<.05$.

\section{Profit points}

The two-factorial ANOVA with the within-factor cognitive frame (loss vs. gain-frame) and the between-factor goal condition (control, goal intention, and implementation intention) on individual profit points revealed a significant main effect of the within-factor cognitive frame, $F(1,42)=13.62, p<.01$. There was no significant main effect of the goal condition factor, $F(2,42)<1.0, n s$. More importantly, there was a significant interaction effect between cognitive frame factor and the goal condition factor, $F(2,42)=3.50, p<.05$ (Table 1$)$. This interaction remained significant when either joint profits or distributed issues were added as a covariate; $F(2,41)=4.25, p<.05$, and $F(2,41)=4.57, p<.05$, for number of distributed issues and joint profits as a covariate, respectively.

We explored the significant interaction effect by conducting further contrast analyses on the difference scores in profits within each pair of negotiators, subtracting the profits of the gain-frame from the profits of the loss-frame negotiation partner. A positive score thus indicates an unfair (i.e., unequal) agreement in favor of the loss-frame participant, whereas a negative score indicates an unfair agreement that is advantageous to the gain-frame

Table 1

Profit points for mixed-frame pairs of negotiators (Study 1)

\begin{tabular}{lccc}
\hline & \multicolumn{2}{c}{ Experimental condition } \\
\cline { 2 - 4 } & Control & Goal intention & Implementation intention \\
\hline Gain-frame & 29.80 & 31.80 & 34.53 \\
Loss-frame & 37.20 & 35.60 & 35.06 \\
Difference score & $7.40_{\mathrm{a}}$ & $3.80_{\mathrm{a}, \mathrm{b}}$ & $.53_{\mathrm{b}}$ \\
\hline
\end{tabular}

Note. Difference scores in a given row with different subscripts differ at $p<.05$. 
participant. A contrast analysis comparing the implementation intention group with the control group on differences in individual profits within each pair of negotiators was significant, $t(28)=2.49, p<.05$, whereas no significant result emerged when comparing the goal intention group with the control group, $t(28)=1.25, n s$. There was also no significant difference between the goal intention group and the implementation intention group, $t(28)=1.56, n s$.

Further analyses on the differences in profits between the gain-frame and loss-frame negotiators within each experimental condition indicated the following results: loss-frame negotiators achieved significantly higher profits than gainframe negotiators within both the control, $t(14)=3.09$, $p<.01$, and the goal intention condition, $t(14)=2.39$, $p<.05$. However, this difference did not reach significance in the implementation intention condition, $t(14)=0.39, n s$.

\section{Correlation analyses}

Profits of gain-frame and loss-frame participants correlated positively with each other, $r=.66, p<.01$. Apparently, within pairs of negotiators making high individual profits was linked to allowing one's negotiation partner to also make high profits. This finding was due to the fact that some pairs of negotiators managed to distribute many regions, villages, and towns resulting in higher profits for both negotiation partners, whereas other pairs of negotiators failed to distribute many regions, villages, and towns resulting in low profits for both negotiation partners.

\section{Discussion}

In line with previous findings (e.g., Bottom \& Studt, 1993), and supporting the assumption of the resistance hypothesis, loss-frame negotiators in the control condition of the present study achieved a negotiation outcome that clearly favored them rather than their counterparts (i.e., loss-frame participants obtained higher individual profits than their gain-frame counterparts). This unfair imbalance was less pronounced when the negotiation task was approached with an assigned fairness goal. Importantly, however, participants needed to furnish this goal with ifthen plans that spelled out how the adopted fairness goal is to be implemented in order to abolish any imbalance (i.e., arrive at a negotiated solution that benefited both negotiators equally well). One needs to keep in mind that our negotiation task with an odd number of different negotiation issues (i.e., 5 cornfield, 7 pastures, 7 mountain regions) and additional villages and towns on some of the regions made it very challenging to find balanced negotiation agreements.

In summary, results of Study 1 support our hypothesis that if-then planning shields goal pursuit (i.e., the pursuit of fairness in an upcoming negotiation) from the negative influences of loss framing thus helping negotiators to find balanced agreements in a same-preferences negotiation task. In a same-preferences negotiation setting (i.e., negotiators have the same-preferences for the negotiation issues) as used in Study 1, negotiators can increase joint outcomes by finding balanced negotiation agreements. In a differentpreferences negotiation setting negotiators may in addition increase their joint outcomes by applying the cognitive demanding strategy of logrolling (i.e., increasing negotiation outcomes by trading the less preferred issues for the more preferred). Therefore, in our second study we changed our negotiation task from a same-preferences to a differentpreferences negotiation context. In Study 2, we were thus able to test a further beneficial consequence of controlling goal pursuit via implementation intentions, that is, cognitive capacity stays untaxed. By delegating the control of goal-directed behavior to anticipated situational cues, action control becomes efficient and thus sufficient cognitive capacity is left to process information that is necessary to achieve one's desired goal. Accordingly, in Study 2 we hypothesized that participants with prosocial goals that are furnished with implementations intentions should be particularly effective in using the integrative negotiation strategy of logrolling.

\section{Study 2: Control of loss-frame effects in same-frame negotiations}

The Dual Concern Model (Pruitt \& Carnevale, 1993; Pruitt \& Rubin, 1986) suggests that problem solving is most likely to occur if negotiators have both a high level of prosocial motivation and a high level of resistance to concession making. Given that loss frames induce a resistance to concession making, one might want to predict that loss-frame negotiators who strive to attain prosocial goals are particularly likely to engage in problem solving behavior such as logrolling. However, previous research (Olekalns, 1994; Olekalns, 1997) indicates that a cognitive loss-frame may also function as a strong cognitive barrier that makes negotiators lose track of their prosocial goals. Still, if loss-frame negotiators set themselves prosocial goals and furnish them with respective implementation intentions, this disadvantage of negotiating on the basis of a loss-frame should completely vanish. To test this shielding hypothesis, we asked one group of pairs of negotiators to form mere prosocial goals, and a second group to furnish such goals with respective implementation intentions; both groups were then subjected to a frame manipulation, whereby both members of the pair received a loss-frame manipulation. We also established two control conditions: a first control condition contained pairs of negotiators who were not assigned prosocial goals and asked to negotiate under a loss-frame; the second control condition also consisted of pairs of negotiators who were not assigned prosocial goals, but these pairs of negotiators were asked to negotiate under a gain-frame. These two control conditions were needed to establish the negative influence of loss vs. gain frames on joint profits. In addition, we wanted to use the loss-frame control condition as a comparison group for the two critical experimental groups (i.e., the prosocial goal group and the prosocial goal plus implementation intention group). 
We hypothesized that pairs of loss-frame negotiators with a prosocial goal intention should manage to reduce the resistance to concession making arising from the lossframe negotiation context, but that only negotiators who furnished their prosocial goal intentions with respective implementation intentions should be successful in completely abolishing the negative impact of the loss-frame negotiation context (i.e., show a negotiation performance that is not different from that of gain-frame negotiators). In addition, action control via implementation intentions has been found to be very efficient (Gollwitzer \& Sheeran, 2006). For instance, in an attempt to test the hypothesis that implementation intentions create strategic automaticity that also extends to the feature of efficiency of action control, Brandstätter et al. (2001; Studies 3 and 4) conducted experiments indicating that implementation intentions allow the planned response to be enacted with little cognitive resources (i.e., even under high cognitive load created by a difficult dual task). Accordingly, we expected that pairs of loss-frame implementation intention negotiators would have the cognitive capacities to apply the integrative negotiation strategy of logrolling. Therefore, we predicted that pairs of negotiators who had formed implementation intentions should be most successful in systematically exchanging concessions on integrative issues (i.e., negotiators increase their overall outcomes by trading the less preferred issues for the more preferred).

\section{Method}

\section{Participants}

One hundred and twenty male students with different academic majors (physics, economy, law, education, etc.) at the University of Konstanz, Germany, aged between 20 and 32 years (median age was 25) were recruited for this study. All participants received $5 €$ (approximately $\$ 5$ ) for remuneration. Participants were recruited through leaflets, and randomly paired and assigned to experimental conditions.

\section{Design}

The current study followed a 2 within (negotiation role: orange nation vs. blue nation) $\times 4$ between (experimental condition: gain-frame only group, loss-frame only group, loss-frame prosocial goal group, and loss-frame prosocial implementation intention group) factorial design.

\section{Procedure and materials}

As in the first study, participants arrived at the laboratory in pairs and were introduced to the negotiation task presented in Study 1. There were several differences between the paradigm used in Study 1 and the present paradigm: this time the island consisted of 29 regions ( 7 cornfield, 7 forest, 7 mountains, and 8 pasture regions) and no towns or villages were added to the regions. The paradigm of Study 2 allowed for integrative agreements: representatives of the blue nation were informed (the counterpart was kept blind to this information) that on their main land they would already possess numerous forests, but lack mountain regions. For the representative of the blue nation, mountains were therefore valued 3 points, whereas forests were only valued 1 point. Representatives of the orange nation were told (again, the counterpart was kept blind to this information) that they already owned numerous mountain regions, but were lacking forests. Therefore, forests were valued 3 points, whereas mountains were valued only 1 point. Furthermore, both participants were informed that their countries were in a very strong need of cornfields (each cornfield was therefore valued 4 points for both representatives), but only in a modest need for pastures (each pasture was therefore valued only 2 points for both representatives). The pareto optimal solution (i.e., the solution that maximizes the joint profits) allowed for 43 points for each representative (e.g., forests: 0 points blue nation/21 points orange nation; mountains: 21 points blue nation $/ 0$ points orange nation; pastures: 10 points blue nation/6 points orange nation; cornfields: 12 points blue nation/16 points orange nation). The best individual profit was at 72 points (7 points for forests or mountains, respectively; 16 points for pastures; 21 points for mountains or forests, respectively; and 28 points for cornfields). Participant were not informed about differences in their own and their counterparts preferences toward the given negotiation issues, and no hint was given toward the integrative character of the given negotiation task.

As in the first study, outcome frames were manipulated by expressing each region's value as either in terms of positive points (i.e., gain-frame) with respect to a reference value of 0 points or in terms of negative points (i.e., lossframe) with respect to a reference value of 72 points (i.e., the total value of the island). In the loss-frame condition, all of the island's regions were already marked by the flags of both nations. If participants agreed on the ownership of a given region, the losing participant had to remove his flag. In the gain-frame condition, island regions were not marked by any nation's flag. If participants agreed on the possession of one region, the gaining participant was allowed to put his flag on the region.

Before receiving detailed instructions on the procedural aspects of the negotiation, participants in the goal intention and the implementation intention condition were assigned prosocial goal and plans, respectively. As indicated by previous research on social value orientations (e.g., De Cremer \& Van Lange, 2001; Van Lange, 1999), a prosocial motivation does not only become apparent in fair negotiation behavior but also in a high level of cooperation with one's negotiation partner. Therefore, in this second experiment we asked participants to form prosocial goals in terms of cooperation rather than fairness. Participants of the prosocial goal intention group were instructed to set themselves the following goal: "I want to cooperate with my counterpart!" Participants of the implementation intention condition were in addition instructed to make the following plan: "And if I receive a proposal on how to share the island, then I will make a cooperative counterproposal!" The two 
control conditions (loss-frame control group, gain-frame control group) did not get assigned any goals or plans.

As the negotiation task was less complex as in Study 1 (no villages and towns were involved in the negotiation task), negotiation time was reduced to a period of $10 \mathrm{~min}$ (with a warning beep presented at $8 \mathrm{~min}$ ) and participants were informed that they were not to win (gain-frame condition) or lose points (loss-frame conditions) for those regions where they failed to settle ownership. After the negotiation was ended, a questionnaire was handed out to find out whether the gain-frame versus loss-frame manipulation was successful and whether the manipulation of the assigned prosocial goal and the implementation intention produced a stable commitment to the assigned goals and plans, respectively. Items and scales for the manipulation check used in this second experiment were the same as in Experiment 1 .

\section{Results}

As in Study 1, all of the analyses used the degrees of freedom related to the pairs of negotiators. In other words, the unit of analysis was again pairs of negotiators.

\section{Manipulation check}

The 2 (blue vs. orange nation) $\times 4$ (experimental condition: gain-frame only, loss-frame only, loss-frame goal intention, loss-frame implementation intention) ANOVA on outcome focus (i.e., maximizing gains versus minimizing losses) revealed a significant main effect for the between factor experimental condition, $F(3,56)=5.29, p<.01$. Participants of the gain-frame only group $(M=2.70$; $S D=4.38$ ) reported a higher importance of maximizing gains as compared to minimizing losses than participants of all three of the loss-frame conditions: loss-frame only group $(M=-1.14, S D=1.93), t(28)=3.10, p<.01$.

The two-factorial ANOVA on the commitment towards the assigned prosocial goal revealed a significant main effect for the between factor experimental condition, $F(3,56)=5.51, p<.01$. Participants of the two conditions who were assigned the prosocial goal (i.e., the loss-frame goal intention group and the loss-frame implementation intention group) reported a higher goal commitment $(M=7.35, S D=1.20)$ than participants of the two other conditions $(M=5.72, \quad S D=1.79), \quad t(57)=4.09, \quad p<.01$. Again, participants of the loss-frame goal intention group and participants of the loss-frame implementation inten- tion group did not differ in the reported commitment towards the assigned prosocial goal, $t<1.0$.

The two-factorial ANOVA on the commitment towards the assigned implementation intention also revealed a significant main effect, $F(3,56)=4.26, p<.01$. Participants in the loss-frame implementation intention group who were assigned this plan $(M=7.66, S D=1.54)$ reported a higher respective commitment than participants of the other three groups who were not assigned this plan $(M=6.15$, $S D=1.87), t(28)=2.80, p<.05$.

\section{Profit points}

The 2 (blue vs. orange nation) $\times 4$ (experimental condition: gain-frame only, loss-frame only, loss-frame goal intention, loss-frame implementation intention) ANOVA on the achieved profits revealed a significant main effect of experimental condition, $F(3,56)=3.95, p<.01$ (Table 2 ). As expected, there was neither a significant main effect for negotiation role, nor a significant interaction effect, both $F_{\mathrm{S}}<1.20$.

Contrast analyses revealed a significant difference between the loss-frame only group and the gain-frame only group, $t(58)=3.12, p<.01$, indicating that loss-frame pairs of negotiators achieved lower joint profits than gain-frame pairs. Even though pairs of negotiators in the loss-frame goal intention group achieved higher joint profits than pairs of negotiators in the loss-frame only group, this increase in joint profits was not significant, $t(28)=1.12, n s$. Most importantly, however, pairs of negotiators of the lossframe implementation intention group achieved significantly higher joint profits than pairs of negotiators of the loss-frame only group, $t(28)=2.39, p<.05$. Comparing the gain-frame only group with the loss-frame goal intention group revealed a significant difference, $t(28)=2.07, p<.05$. No other contrast effect became significant, all $t \mathrm{~s}<1.40$.

\section{Further analyses: processes underlying the implementation intention effect}

As mentioned before, one effective way to increase joint negotiation outcomes is the cognitive demanding strategy of logrolling. We predicted that pairs of negotiators who had formed implementation intentions should be more successful in applying negotiation strategy of logrolling than negotiators of any other group, given that forming implementation intentions saves cognitive resources. In order to assess negotiators' use of the logrolling strategy, we computed the following index: for the representatives of the

Table 2

Profits points for same-frame pairs of negotiators (Study 2)

\begin{tabular}{lcccr}
\hline & \multicolumn{3}{c}{} & \multicolumn{2}{c}{ Experimental condition } \\
\cline { 2 - 5 } & Gain-frame only & Loss-frame only & Loss-frame goal intention & Loss-frame implementation intention \\
\hline Orange nation & 34.93 & 23.27 & 28.60 & 34.40 \\
Blue nation & 35.33 & 25.60 & 28.80 & 32.27 \\
Sum score & $70.26_{\mathrm{a}}$ & $48.87_{\mathrm{b}}$ & $57.40_{\mathrm{a}, \mathrm{b}, \mathrm{c}}$ & \\
\hline
\end{tabular}

Note. Joint outcomes and logrolling-scores in a given row with different subscripts differ at $p<.05$. 
blue nation we counted how many mountain regions (high own preference) they took possession of and subtracted from this number the number of forests (high other preference) taken away from their counterparts. Analogously, for the representatives of the orange nation we counted how many forests (high own preference) they took possession of and subtracted the mountain regions (high other preference) taken away from their counterparts. This index describes how well the negotiation partners managed finding integrative solutions that respect their differential preferences for mountain regions and forests. It ranged from +7 (receiving all regions with high personal preference without taking away regions with high other preference) to -7 (receiving no region with high own personal preference while taking away all regions with high other preference).

The $2 \times 4$ ANOVA on this logrolling-index revealed a significant main effect of experimental condition, $F(3,56)=10.81, p<.01$. There was neither a significant main effect for negotiation role, nor a significant interaction between this factor and experimental condition, both $F_{\text {s }}<1.5$. Participants of the loss-frame implementation intention group $(M=5.06, S D=2.07)$ reached higher logrolling scores than participants of the gain-frame only group $(M=2.93, S D=2.75), t(56)=2.58, p<.05$, the lossframe only group $(M=1.83, S D=2.38), \quad t(56)=3.91$, $p<.01$, and the loss-frame goal intention group $(M=0.70$, $S D=1.67), t(56)=5.29, p<.01$. In sum, pairs of negotiators of the loss-frame implementation intention group were more successful in finding integrative solutions than pairs of negotiators of any other group.

In order to test our hypothesis that loss-frame pairs of negotiators with prosocial goals and respective implementation intentions achieved their higher outcomes as compared to the loss-frame only participants via the strategy of logrolling, we used the multiple regression mediation approach suggested by Baron and Kenny (1986). For this purpose, we recoded belonging to the loss-frame implementation intention group or the loss-frame only group as a contrast coded variable $(1,-1)$. First, a direct relationship between the achieved joint profits and the contrast coded variable was found, $\beta=.41, t(28)=2.39, p<.01$. Second, the contrast coded variable was predictive of the logrollingindex score, $\beta=.59, t(28)=3.95, p<.01$. Third, when the logrolling-index score and the contrast coded variable were entered simultaneously, logrolling-index scores were predictive of achieved joint profits, $\beta=.69, t(28)=4.04, p<.01$. Moreover, the direct relationship between the contrast coded variable and joint profits became nonsignificant, $\beta=-.007, t(28)=0.04$, ns. Using the Sobel-test (Sobel, 1982), we found that the reduction in effect size due to the logrolling-index score was statistically significant, $z=2.82$, $p<.01$. In addition, to test the alternative hypothesis that the high joint profits in the implementation intention lossframe condition were achieved by the simple strategy of nonsystematic concession making (i.e., distributing as many issues as possible), we used the same multiple regression mediation analysis described above. However, as the con- trast coded variable was not predictive of the number of distributed issues, $\beta=.28, t(28)=1.57, n s$, this latter variable does not seem to qualify as a potential mediator.

We also explored whether the beneficial effects of gainframes as compared to loss-frames are mediated by either using the strategy of logrolling or the strategy of nonsystematic concession making (i.e., number of distributed regions). For this purpose, we recoded belonging to the gain-frame only group or the loss-frame only group as a contrast coded variable $(1,-1)$. First, a direct relationship between the achieved joint profits and the contrast coded variable was found, $\beta=.50, t(28)=3.06, p<.01$. However, the contrast coded variable was not predictive of the logrolling-index score, $\beta=.21, t(28)=1.16, n s$, indicating that this latter variable does not qualify as a potential mediator. When looking at the number of distributed issues, regression analyses revealed that the contrast coded variable was predictive of the number of distributed issues, $\beta=.58$, $t(28)=3.78, p<.01$, which in turn was predictive of the achieved joint profits, $\beta=.98, t(28)=14.72, p<.01$. Moreover, the direct relationship between the contrast coded variable and joint profits became nonsignificant, $\beta=-.018$, $t(28)=1.14$, ns. Using the Sobel-test (Sobel, 1982), we found that this reduction in effect size was statistically significant, $z=3.66, p<.01$.

Apparently, loss-frame pairs of negotiators with prosocial goals and respective implementation intentions achieved their heightened negotiation outcomes in a different way than gain-frame pairs of negotiators: whereas the gain-frame group achieved their high level of joint profits via the strategy of eagerly distributing the issues at hand, pairs of negotiators with a loss-frame and implementation intentions did so by using the strategy of logrolling.

\section{Discussion}

The present study replicated previous findings that pairs of loss-frame negotiators achieve lower profits than pairs of gain-frame negotiators in an integrative negotiation task (e.g., Bazerman et al., 1985; Neale \& Bazerman, 1985). Importantly, however, whereas a mere prosocial goal only tended to reduce the obstructive effects of loss framing, implementation intentions formed to support this goal completely abolished it. The direct action control induced by implementation intentions apparently hindered loss framing and its associated resistance to concession making to take effect in the negotiation task (shielding hypothesis).

Most interestingly, pairs of loss-frame negotiators, who had formed prosocial cooperation goals and had furnished these goals with respective implementation intentions, used the integrative negotiation strategy of logrolling more effectively than negotiators of any other group. This is particular noteworthy, as the instruction on the prosocial goal intention and the respective implementation intentions only asked participants to cooperate with their counterpart without explaining how to translate this cooperation into concrete negotiation behavior (e.g., cooperation by making 
nonsystematic concessions, making balanced counteroffers, accepting the counterpart's demands, etc.). Moreover, participants were not informed about the integrative potential of the given negotiation task. As previous research on implementation intentions (e.g., Brandstätter et al., 2001; Lengfelder \& Gollwitzer, 2001) has pointed out, action control by implementation intentions is efficient in the sense that it delegates action control to the critical cues, thus setting free cognitive capacities that can be used to process relevant information. In the present study it appears, then, that pairs of negotiators who had formed implementation intentions achieved their high joint profits by being able to use the cognitive demanding strategy of logrolling. Having their negotiation behavior controlled by implementation intentions saved cognitive resources that could be used successfully to tackle the complex problem solving task of finding integrative solutions (Pruitt \& Carnevale, 1993). This is particularly noteworthy, as most inexperienced negotiators start negotiations with a so-called fixed-pie assumption (i.e., negotiators falsely assume that their own and their counterparts' preferences are diametrically opposed; Thompson \& Hrebec, 1996) that precludes integrative solutions.

Although the present experiment confirmed our hypothesis that the self-regulation strategy of forming implementation intentions qualifies as a powerful tool in complex social interaction situations such as negotiations, Experiments 1 and 2 cannot yet answer the question of how implementation intentions produced their beneficial effects during the course of the negotiation. Furthermore, from solely looking at negotiation outcomes one might want to suggest experimenter demand as an alternative explanation of the observed implementation intention effects. Even though an experimenter demand interpretation of the findings of Experiment 2 should find it difficult to explain the observed differences in negotiators' achieved logrolling scores (i.e., experimenter demand should be reflected in higher rates of concession making rather than in the application of the logrolling strategy), Study 3 will have a closer look at the actual negotiation process to counter experimenter demand explanations.

Based on previous research on framing effects in negotiations (summary by De Dreu et al., 1995), we assumed that loss-frame pairs of negotiators facing a resistance to concession making should benefit from the self-regulatory strategy of forming implementation intentions. However, from Experiments 1 and 2 it remains unclear whether the beneficial effect of implementation intentions is limited to a loss-frame negotiation context. Therefore, in our third experiment we added a group of gain-frame pairs of negotiators who were asked to form prosocial implementation intentions.

\section{Experiment 3: implementation intentions and the control of} loss-frame effects over the course of negotiation

The purpose of the third experiment was threefold: first, it was tested whether prosocial goal intentions and respec- tive implementation intentions would unfold their beneficial effects even in negotiation settings in which negotiators are not faced with a cognitive barrier (a loss-frame) that burdens negotiation. Accordingly, not only loss-frame but also gain-frame pairs of negotiators where asked to form prosocial goals and respective implementation intentions. Second, although the experimental paradigm of Experiments 1 and 2 was obviously interesting enough to engage participants' motivation and attention, we made an effort to increase the personal significance of the negotiation task by (a) giving participants monetary incentives, and (b) using a cover story that was more related to participants' understanding of real world negotiations. Third, the negotiation task of the previous two experiments only allowed for the analysis of achieved outcomes at the end of the negotiation. In this third experiment, we did not only focus on the achieved outcomes but also continuously recorded the quality of exchanged offers over the whole course of negotiation, starting with participants' first offers and ending with participants' final agreements. For this purpose, we used a computer-mediated negotiation setting that allowed us to analyze how implementation intentions produce their effects in the ongoing negotiation process.

As with Experiment 2, we predicted that the resistance to concession making in loss-frame pairs should only be completely abolished by planning in advance on how to implement prosocial cooperation goals, whereas forming mere prosocial cooperation goals should be less effective. Going beyond Experiment 2, we also asked part of the gain-frame pairs of negotiators to form prosocial goals, and another part to form corresponding implementation intentions. As willpower in terms of self-regulation by goals and plans unfolds its effects only if barriers or hindrances are encountered, but fails to make a difference when goal attainment is easy and goal implementation runs off smoothly (Gollwitzer \& Sheeran, 2006; Mischel et al., 1996), we did not expect prosocial goal intentions or implementation intentions to improve negotiation outcomes in gain-frame pairs of negotiators.

In this third experiment, we also analyzed exchanged offers over the course of the negotiation. We expected that prosocial implementation intention instructions affect profit points (exchanged offers) over the course of negotiation only within the loss-frame negotiation context: whereas loss-frame pairs of negotiators should not differ in their profit points (exchanged offers) at the start of the negotiation (i.e., negotiation round 1, in which negotiators made their first offers without receiving counteroffers from their negotiation partners), in subsequent negotiation rounds loss-frame pairs of negotiators of the implementation intention condition should reveal a pronounced progress in profit points as compared to loss-frame pairs of negotiators without prosocial if-then plans. More specifically, we predicted that loss-frame pairs of negotiators should experience a strong resistance to concession making. However, planning in advance to behave in a prosocial manner when one receives a request from the negotiation 
partner, should help negotiators to overcome their resistance to concession making over the enduring course of negotiation.

Moreover, in line with the results of Experiment 2, we expected that pairs of negotiators who formed prosocial implementation intentions should also be more successful in applying the integrative negotiation strategy of logrolling over the enduring course of negotiation than pairs of negotiators without prosocial if-then plans. In line with previous research on the efficiency of action control via implementation intentions, we expected that controlling one's negotiation behavior by the self-regulation strategy of forming implementation intentions should save cognitive resources that can be used to discover the integrative solutions incorporated in the negotiation task. More specifically, we expected that pairs of negotiators who formed implementation intentions should reveal a pronounced progress in achieved logrolling scores over the enduring course of negotiation as compared to pairs of negotiators without prosocial if-then plans.

\section{Method}

\section{Participants}

One hundred and eighty-six students of the University of Kiel (Germany) with different academic majors (e.g., law, education, business, and biology), aged between 18 and 46 years (the median age was 24.6 years) participated in the experiment. For remuneration, participants received 7 Euro (approximately \$7). Recruiting was done through leaflets.

\section{Design}

The present study follows a 2 (negotiation role: Heir A vs. Heir B) $\times 2$ (cognitive frame: loss vs. gain $) \times 3$ (experimental condition: control group vs. prosocial goal intention group vs. prosocial implementation intention group) mixed-factor design with cognitive frame and experimental condition as between-subject variables and negotiation role as a within-subject variable. Analyses on the course of negotiation were conducted by adding the within-subject factor of negotiation round (first, second, third, fourth negotiation round, and final agreement).

\section{Procedure and negotiation task}

For each experimental session, eight participants were recruited through leaflets. Upon arrival at the laboratory, each participant was individually taken to one of eight cubicles, each of them equipped with a networked computer. Each of the eight computers was paired with one of the other computers, resulting in four computer-mediated negotiation settings within each experimental session. Participants received all instructions for the upcoming negotiation task on their computer screen.

At the beginning of the experiment, participants were asked to imagine that they recently had received a letter from a notary. In this letter they were informed that a distant relative had died and left them an inheritance of shares from six different companies (Company AC-Media, BKFashion, CC-Consulting, Digital Days, Europe Air, and Ferry Cooperation; hereafter called Companies A-F). The letter further informed participants that this inheritance was to be distributed between them and another person who was also remembered in the relative's will. The letter also informed participants that both heirs would have equally entitled claims for the inherited shares.

Participants were assigned the role of either Heir A or Heir B. They were asked to imagine that in preparation for the upcoming negotiation each heir had asked a financial consultant to rate the shares on different dimensions such as their current value, the prosperity of the companies, or the expected progress of the shares in the future. Participants were then given a list that displayed the shares of the six companies, each of them valued by their financial consultant on a scale ranging from 1 (very low value) to 6 (very high value). Participants in the role of Heir A were told that their financial consultant evaluated shares of Company A, $\mathrm{B}, \mathrm{C}, \mathrm{D}, \mathrm{E}$, and $\mathrm{F}$ with 2, 4, 1, 3, 5, and 6 points, respectively. Participants in the role of Heir B were told that their financial consultant evaluated shares of Company A, B, C, D, E, and $F$ with $4,2,1,5,3$, and 6 points, respectively. Participants were not informed about the evaluations of their counterpart's financial consultant.

Following the information on their financial consultant's evaluations, the details of the negotiation task were explained to participants on the computer screen. In the upper part of the computer screen, participants saw six different pull-down bars each of them labeled with one of the six company names (e.g., AC-Media, BK-Fashion). Just below the company names the financial consultant's evaluations of the respective company shares were indicated by points $(1=$ very low evaluated shares, $6=$ very high evaluated shares). Participants were informed that shares for each type of company were available in numbers of 10 . Consequently, each pull-down bar could be adjusted to a value between 0 and 10. Points below each pull-down bar indicated the score point resulting from the number on the adjusted pull-down bar multiplied by the corresponding value of the respective type of shares (e.g., if Heir A with a cognitive gain-frame asked for 6 out of 10 shares of Company B, 6 shares multiplied by 4 points $=24$ points were displayed below the respective pull-down bar). Finally, total sum scores for all types of shares were indicated on the far right of the computer screen. Within each negotiation round participants had to make offers on all six types of shares (Company A-F). Furthermore, within each negotiation round participants were given the option to attach text messages to their offers and send them towards their negotiation partner.

In the lower part of the computer screen, the counterparts' offers were displayed in the same way as it was done for participants' own offers: six pull-down bars labeled with the six company names, points below each pull down bar indicating sum scores for each type of shares, and total sum score for all types of shares on the far right of the computer 
screen. By comparing the upper and lower part of the computer screen participants could easily explore differences between their own and their counterparts' offers and detect how many points they could gain/lose for both, their own, and their counterparts' offers. Finally, participants were informed that they could increase their chances to win one of several cash prizes (each 25 Euro) depending on the quality of their individually achieved negotiation outcomes. Participants were further told that the chance to win one of the cash prizes was independent of the other participants' negotiation outcomes.

The negotiation task was started with both participants making a first offer. Thereafter, participants took turns in sending offers to their counterpart over several negotiation rounds, each round consisting of one offer and one counteroffer. After the fourth negotiation round, participants were informed that from now on they could choose between three different types of actions: making a further offer, accepting the counterpart's offer, and sending off a final offer. If participants decided to make a further offer, negotiation went on as explained above. If participants decided to accept their counterparts' offer, the counterparts received a respective message and the negotiation was ended. If participants decided to make a final offer, their counterpart was informed about this choice and asked whether he would accept this final offer or whether he would like to end the negotiation by making his own final offer. Participants were informed that they were not to win (gain-frame condition) or lose points (loss-frame conditions) for those shares where they failed to find agreements. Negotiation time was not limited. The best individual outcome was at 210 points, and the pareto optimal solution allowed for 125 points for each negotiator (250 points for pairs of negotiators).

As in the second study, outcome frames were manipulated by expressing the value of the shares in either positive points (i.e., gain-frame) or negative points (i.e., loss-frame). Within the gain-frame condition, participants had to indicate for each type of shares how many points they would like to gain. Points for each type of shares as well as the total sum score of points were displayed in terms of positive values with respect to a reference point of 0 points. Within the loss-frame condition, participants had to indicate for each type of shares how many points they were willing to lose. Points for each type of shares as well as the total sum score of points were displayed in terms of negative values with respect to a reference point of 210 .

The three experimental conditions were varied as follows: participants in the prosocial goal intention group were instructed to set themselves the following goal: "I want to cooperate with my negotiation partner!" In the implementation intention condition, participants were instructed to make the additional plan: "And if I receive a proposal of my negotiation partner, then I want to cooperate with my negotiation partner!" Participants of the control condition were not assigned any goals or plans.

Finally a questionnaire was handed out to find out whether the gain-frame versus loss-frame manipulations produced a stable cognitive orientation, and whether the manipulation of the assigned prosocial goal and the respective implementation intention produced a stable commitment to the assigned goals and plans, respectively. To check on the frame manipulation participants were asked: "How important is it for you to maximize gains and minimize losses?" The 7-point answer scale reached from -3 (minimize losses) to +3 (maximize gains). To check on the prosocial goal manipulation, we asked: "How committed do you feel to the goal to cooperate?" Finally, the commitment to the implementation intention was assessed by: "How committed do you feel to the plan to cooperate with your negotiation partner if you receive a proposal?" Manipulation check items for goal and implementation intention commitment items were accompanied by a 7-point answer scale reaching from 1 (not at all) to 7 (very).

\section{Results}

As in the previous two studies, all of the analyses used the degrees of freedom related to the pairs of negotiators. In other words, the unit of analysis was pairs of negotiators.

\section{Manipulation check}

The 2 (Heir A vs. Heir B) $\times 2$ (gain-frame vs. lossframe) $\times 3$ (control group vs. goal intention vs. implementation intention) ANOVA on outcome focus (i.e., maximizing gains versus minimizing losses) revealed a significant main effect for the between factor cognitive frame, $F(1,90)=65.39$, $p<.01$. Participants of the gain-frame condition $(M=1.68$; $S D=1.40$ ), reported a higher importance of maximizing gains as compared to minimizing losses than participants of the loss-frame condition $(M=-0.96 ; S D=1.75)$. No other main or interaction effects were significant, all $F_{\mathrm{S}}<1.0$.

The three-factorial ANOVA on the commitment towards the assigned prosocial goal revealed a marginally significant main effect for the between factor experimental condition, $F(2,90)=2.49, p=.08$. Participants of the two conditions who were assigned the prosocial goal $(M=5.57$, $S D=1.08)$ reported a higher goal commitment than participants of the control conditions $(M=4.98, S D=1.41)$, $t(94)=2.24, p<.05$. Participants of the goal intention group and participants of the implementation intention group did not differ in the reported commitment towards the assigned prosocial goal, $t<1.0$. No other main or interaction effects were significant, all $F$ s $<2.0$.

The three-factorial ANOVA on the commitment towards the assigned implementation intention revealed a significant main effect, $F(2,90)=3.28, p<.05$. Participants of the implementation intention group $(M=5.21$, $S D=1.05$ ) reported a higher commitment toward the given plan than participants of the other two groups who were not assigned a plan $(M=4.66, S D=1.30), t(94)=2.09$, $p<.05$. Participants of the goal intention group and participants of the control group did not differ in the reported commitment, $t<1.0$. No other main or interaction effects were significant, all $F_{\mathrm{s}}<1.5$. 


\section{Negotiation Outcomes}

\section{Profit points}

As in the previous experiments, profit points were computed by summing up the points for negotiation issues (i.e., shares) for which negotiators had managed to find agreements. The three-factorial ANOVA on profit points revealed a significant main effect of the factor experimental condition, $F(2,90)=4.00, p>.05$, and a marginal significant main effect of the factor of cognitive frame, $F(1,90)=3.24, p=.07$. These main effects were qualified by a marginally significant twoway interaction $F(2,90)=2.80, p=.06$. No other main or interaction effects were significant, all $F \mathrm{~s}<1.0$ (Table 3).

We had predicted that prosocial goals and respective implementation intentions should only unfold their beneficial effects in a loss-frame negotiation setting in which negotiators are faced with a resistance to concession making that undermines their capability to cooperate. In line with Experiment 2, we expected a linear trend within the cognitive loss-frame condition whereas within the cognitive gain-frame condition we did not expect differences between the three experimental conditions. A planned contrast on this predicted pattern (i.e., coding the loss-frame control group with -2 , the loss-frame goal intention group with -1 , the loss-frame implementation intention group with 0 , and all three gain-frame groups with +1) was highly significant, $F(1,90)=10.70, p>.001$.

We continued our data analysis by performing two separate analyses on the effects of prosocial goals and respective implementation intentions, one within the loss-frame condition and another within the gain-frame condition. As expected analyses within the loss-frame condition revealed a highly significant main effect for the factor of experimental condition, $F(2,90)=5.89, p<.01$, whereas there was no significant main effect for the factor of experimental condition within the gain-frame condition, $F(2,90)=0.91$, ns. Further contrast analyses within the loss-frame condition revealed that pairs of negotiators of the implementation intention group achieved higher joint profits than pairs of negotiators of both the control and the mere goal intention group, $t(90)=3.42, p<.01$, and $t(90)=1.87, p<.05$ (onetailed), respectively. There was no significant difference between the control group and the mere goal intention group, $t(90)<1.0, n s$.

\section{Further analyses: processes underlying the implementation} intention effect

Analogous to Experiment 2, we analyzed whether the self-regulatory strategy of forming implementation intentions was associated with using the negotiation strategy of logrolling. Logrolling-scores were computed in the following way: for Heir A we counted how many shares of Companies B and E (higher preference of Heir A) were taken into possession and subtracted from this sum the number of shares of Companies A and D (higher preference of Heir B). The logrolling scores for Heir B were computed by counting the number of shares of Companies A and D and subtracting the number of shares of Companies B and E. The logrolling scores ranged from +20 (receiving all shares of companies with higher preferences without taking away shares with lower preferences) to -20 (taking away all shares of companies with lower preferences without receiving any shares of companies with higher preferences).

The three-factorial ANOVA on the logrolling-index revealed a significant main effect of the factor experimental condition, $F(2,90)=3.12, p<.05$. No other main or interaction effects were significant, all $F_{\mathrm{S}}<2.2$.

Further contrast analyses revealed that pairs of negotiators of the implementation intention group $(M=15.71$, $S D=13.32$ ) achieved higher logrolling-index scores than both pairs of negotiators of the control group $(M=8.21$, $S D=12.79), t(90)=2.38, p<.05$, and pairs of negotiators of the goal intention group $(M=9.90, S D=12.20), t(90)=1.85$, $p<.05$ (one-tailed). There was no significant difference between pairs of negotiators of the control group and pairs of negotiators of the goal intention group, $t(90)<1.0$, ns.

In order to test our hypothesis that loss-frame pairs of negotiators with prosocial goals and respective implementation intentions achieved their higher outcomes as compared to the loss-frame only participants via the strategy of logrolling, we again used the multiple regression mediation approach suggested by Baron and Kenny (1986). As in the second experiment, we recoded belonging to the loss-frame implementation intention group and loss-frame control group as a contrast coded variable $(1,-1)$. First, a direct relationship between the achieved joint profits and the contrast coded variable was found, $\beta=.55, t(30)=3.67, p<.01$. Second, the contrast coded variable was predictive of the logrolling-index score, $\beta=.49, t(30)=3.10, p<.01$. Third, when the logrolling-index score and the contrast coded var-

Table 3

Profits points for same-frame pairs of negotiators (Study 3)

\begin{tabular}{|c|c|c|c|c|c|c|}
\hline \multirow[t]{3}{*}{ Dependent variable } & \multicolumn{6}{|c|}{ Experimental condition } \\
\hline & \multicolumn{3}{|c|}{ Loss-frame } & \multicolumn{3}{|c|}{ Gain-frame } \\
\hline & $\begin{array}{l}\text { Control } \\
\text { group }\end{array}$ & $\begin{array}{l}\text { Goal intention } \\
\text { group }\end{array}$ & $\begin{array}{l}\text { Implementation } \\
\text { intention group }\end{array}$ & $\begin{array}{l}\text { Control } \\
\text { group }\end{array}$ & $\begin{array}{l}\text { Goal intention } \\
\text { group }\end{array}$ & $\begin{array}{l}\text { Implementation } \\
\text { intention group }\end{array}$ \\
\hline Heir A & 78.00 & 92.25 & 102.94 & 104.13 & 92.25 & 97.81 \\
\hline Heir B & 75.63 & 86.31 & 105.31 & 96.38 & 92.31 & 107.19 \\
\hline Sum score & $153.63 \mathrm{a}$ & $178.56_{\mathrm{a}, \mathrm{b}}$ & $208.25 \mathrm{c}$ & $200.51_{c}$ & $184.56_{\mathrm{b}, \mathrm{c}}$ & $205.00_{\mathrm{c}}$ \\
\hline
\end{tabular}

Note. Joint outcomes and logrolling-scores in a given row with different subscripts differ at $p<.05$. 
iable were entered simultaneously, logrolling-index scores were predictive of achieved joint profits, $\beta=.43$, $t(30)=2.74, p=.01$. Moreover, the direct relationship between the contrast coded variable and joint profits was considerably reduced to $\beta=.34, t(30)=2.17, p<.05$. Using the Sobel-test (Sobel, 1982), we found that the reduction in effect size due to the logrolling-index score was statistically significant, $z=2.06, p<.05$. As in the second experiment, we also tested whether the heightened joint profits in the implementation intention loss-frame condition were achieved by the strategy of distributing a high number of issues. Again, the contrast coded variable was predictive of the number of distributed issues, $\beta=.42, t(30)=2.60$, $p<.05$. Furthermore, number of distributed issues was predictive of achieved profit points when the contrast coded variable and number of distributed issues were entered into the regression simultaneously, $\beta=.85, t(30)=13.71, p<.01$. Using the Sobel-test, we found that the reduction in effect size due to the number of distributed issues score was statistically significant, $z=2.55, p<.05$. Entering number of distributed regions and logrolling-index scores simultaneously into a multiple regression revealed that both variables independently from each other were predictive of the achieved profit points, $\beta=.80, t(28)=22.65, p<.01$, and $\beta=.30$, $t(28)=7.94, p<.01$, for number of distributed regions and logrolling-index scores, respectively.

As in the second experiment, we also explored whether the higher profits of the gain-frame control group as compared to the loss-frame control group was mediated by using either the strategy of logrolling or the strategy of nonsystematic concession making (i.e., number of distributed regions). For this purpose, we recoded belonging to the gain-frame control group or the loss-frame control group as a contrast variable $(1,-1)$. First, a direct relationship between the achieved joint profits and the contrast coded variable was found, $\beta=.48, t(30)=3.06$, $p<.01$. Second, the contrast coded variable was predictive of the logrolling-index score, $\beta=.41, t(30)=2.53$, $p<.05$, which in turn was predictive of achieved profit points, $\beta=.39, t(30)=2.44, p<.05$. Although the direct relationship between the contrast coded variable and joint profits was reduced to $\beta=.32, t(30)=1.96, p=.05$, the Sobel-test revealed that this reduction in effect size due to the logrolling-index score was not statistically significant, $z=1.75$, ns. This suggests that the logrollingindex does not qualify as a powerful mediator of differences in profit points found between pairs of negotiators of the gain-frame control group and the loss-frame control group. When looking at number of distributed issues as a potential mediator, the contrast coded variable was predictive of the number of distributed issues, $\beta=.43$, $t(30)=2.59, p<.05$, which in turn was predictive of the achieved joint profits, $\beta=.90, t(30)=13.90, \quad p<.01$. Moreover, the direct relationship between the contrast coded variable and joint profits became nonsignificant, $\beta=.10, t(30)=1.60, n s$. Using the Sobel-test, we found that the reduction in effect size due to the number of dis- tributed issues was statistically significant, $z=2.55$, $p<.05$.

Apparently, loss-frame pairs of negotiators with prosocial goals and respective implementation intentions achieved their higher negotiation outcomes by using both strategies, that is, distributing a high number of issues and applying the integrative negotiation strategy of logrolling. In contrast, gain-frame negotiators of the control group achieved their higher negotiation outcomes by simply using the negotiation strategy of distributing a high number of issues.

\section{Course of the negotiation}

The dependent variables of profit points and logrolling were not only recorded at the end of the negotiation task but also after each negotiation round. This allowed us to analyze these dependent variables over time, that is, over the first four negotiation rounds, in which participants were not allowed to end the negotiation by making a final demand or by accepting the counterpart's offer. ${ }^{1}$ We also included final agreements into these analyses. Thus, the course of the negotiation was analyzed from the start of the negotiation (negotiators' first offers) up to the achieved final agreements (negotiation outcomes).

\section{Number of negotiation rounds}

As mentioned before, negotiation time was not limited and participants could negotiate with each other as long as one side ended the negotiation. Analyses on the number of negotiated rounds did not reveal any significant main or interaction effects, all $F \mathrm{~s}<1.0$. On average, pairs of negotiators negotiated over 5.28 negotiation rounds.

\section{Profit points}

Profit points over the course of the negotiation were analyzed with a 2 (cognitive frame) $\times 3$ (experimental condition) $\times 5$ (negotiation round) ANOVA with the latter variable as a within-subject factor. The three-factorial ANOVA revealed a significant main effect for the withinsubject factor negotiation round $(M=123.55, S D=40.31$; $M=148.64, \quad S D=43.40 ; \quad M=159.15, \quad S D=47.87$; $M=171.50, S D=51.67 ; M=188.41, S D=47.77$ for rounds $1-4$ and final agreement, respectively), $F(4,360)=59.28$, $p<.01$, a significant main effect for the between-subject factor cognitive frame $(M=148.52, S D=38.61, M=167.98$, $S D=32.62$, for loss-frame and gain-frame pairs of negotiators, respectively), $F(1,90)=7.34, p<.01$, and a marginally significant three-way interaction, $F(8,360)=1.74, p=.08$ (Figs. 1 and 2).

As mentioned before, we predicted that prosocial goals and corresponding implementation intention should unfold

\footnotetext{
1 The reported results on profit points and logrolling scores did not change when the fifth and sixth negotiation round was included into the statistical analyses. After the sixth negotiation round less than fifty percent of the participants were still negotiating.
} 


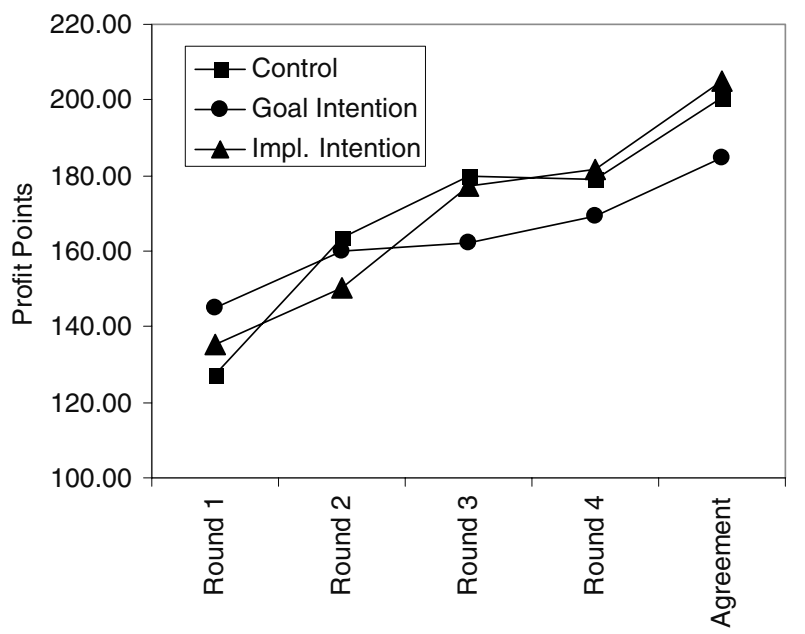

Fig. 1. Course of negotiation in the gain-frame negotiation context: profit points for gain-frame pairs of negotiators of the control group, the goal intention group, and the implementation intention group at the four rounds of negotiation and at the final agreement.

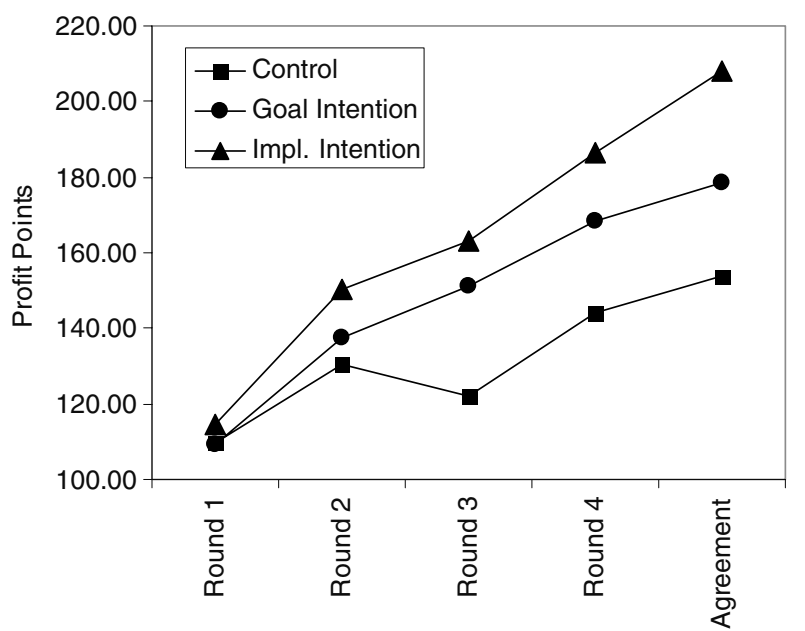

Fig. 2. Course of negotiation in the loss-frame negotiation context: profit points for loss-frame pairs of negotiators of the control group, the goal intention group, and the implementation intention group at the four rounds of negotiation and at the final agreement.

their beneficial effects only within a loss-frame negotiation setting. Therefore, we performed separate ANOVAs for the gain-frame and loss-frame condition. Within the gainframe condition, the within-subject factor of negotiation round revealed a significant main effect, $F(4,180)=22.50$, $p<.01$. As can be seen in Fig. 1, pairs of negotiators in the gain-frame condition systematically increased their profit, irrespective of the factor of experimental condition. Within the loss-frame condition there was also a highly significant main effect of the within-subject factor of negotiation round, $F(4,180)=40.33, p<.01$, but it was qualified by a significant interaction with the between-subject factor of experimental condition, $F(8,180)=2.06, p<.05$. As can be seen in Fig. 2, pairs of negotiators of all conditions improved their profits over the negotiation process. How- ever, this improvement was more pronounced within the prosocial implementation intention condition.

To further decompose the significant two-way interaction within the loss-frame negotiation context, we performed several contrast analyses. First, we analyzed whether loss-frame pairs of negotiators of the three experimental conditions (control group, prosocial goal group, and implementation intention group) differed in profit points in the first negotiation round (i.e., negotiators making a first offer without receiving a counteroffer from their negotiation partner). Contrast analyses did not reveal any significant difference in the first negotiation round, all $t \mathrm{~s}<.05$. Next we analyzed differences in progress of achieving profit points between pairs of negotiators who did form implementation intentions and those who did not form implementation intentions (contrast coding: $-1,-1,+2$ for control group, prosocial goal group and prosocial implementation intention group, respectively). Differences in progress of profit points following the first negotiation round were explored by computing Helmert contrast analyses (Keppel, 1991) comparing the mean of each level of the within-factor 'negotiation round' to the mean of subsequent levels. As expected, comparing profit points of negotiation round 1 to profit points of subsequent negotiation rounds (contrast coding $+4,-1,-1,-1,-1$ ) revealed a significant interaction effect with the contrast coded factor 'experimental condition', $F(2,45)=4.42, p<.05$. Further Helmert contrast coding for subsequent negotiation rounds (i.e., $0,+3,-1,-1,-1 ; 0,0,+2,-1,-1 ; 0,0,0,+1,-1) \mathrm{did}$ not reveal any other significant interaction effects, all $F_{\text {s }}<2.3$. In sum, it appears that after the first negotiation round (i.e., negotiation rounds in which negotiators received a counteroffer form their negotiation partner) lossframe pairs of negotiators of the implementation intention condition differed in the progress of profit points form lossframe negotiators of the two other conditions.

\section{Logrolling-index}

The three-factorial ANOVA on the logrolling-index revealed a significant main effect for the within-subject variable of negotiation round $(M=5.13, S D=7.59 ; M=5.85$, $S D=9.31 ; M=7.92, S D=11.14 ; \quad M=10.02, S D=12.45$; $M=11.28, S D=13.05$ for rounds $1-4$ and final agreement, respectively), $F(4,360)=13.68, p<.01$, that was further qualified by a highly significant interaction with the between-subject variable of experimental condition, $F(8,360)=2.71, p<.01$ (Fig. 3). No other main or interaction effects were significant.

To further decompose the significant two-way interaction, we analyzed differences in the improvement of logrolling scores between pairs of negotiators of the implementation intention group and the two other groups (contrast coding: $-1,-1,+2$ for control group, prosocial goal group and prosocial implementation intention group, respectively). Again, we used Helmert contrast coding (Keppel, 1991). Comparing achieved logrolling scores of negotiation round 1 to achieved logrolling scores of subse- 


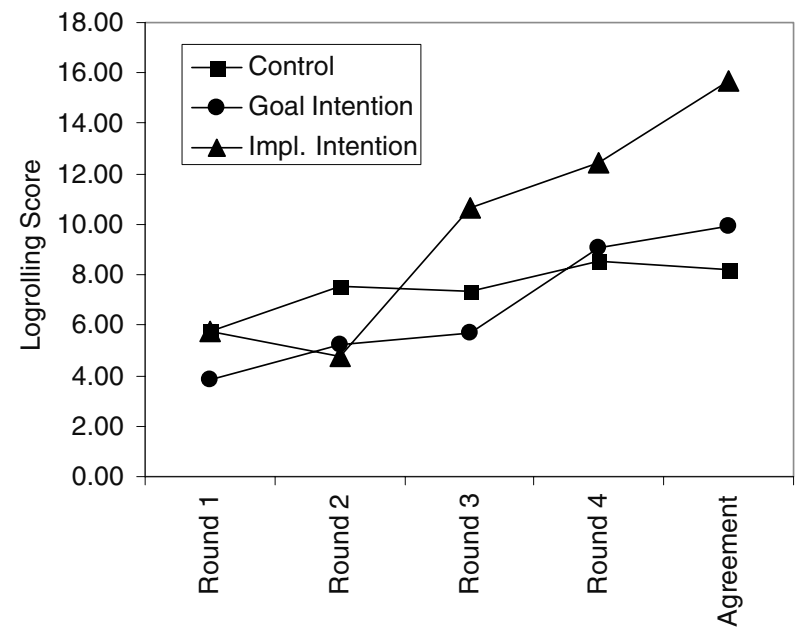

Fig. 3. Course of negotiation: collapsed logrolling scores for gain-frame and loss-frame pairs of negotiators of the control group, the goal intention group, and the implementation intention group at the four rounds of negotiation and at the final agreement.

quent negotiation rounds (contrast coding: $+4,-1,-1,-1$, -1) did not reveal a significant interaction effect with the contrast coded factor of experimental condition, $F(2,45)=.96, n s$. However, comparing achieved logrolling scores of negotiation round 2 to subsequent negotiation rounds (contrast coding: $0,+3,-1,-1,-1$ ) revealed a significant interaction effect, $F(2,45)=5.47, p<.01$, indicating that after the second negotiation round pairs of negotiators of the implementation intention condition were more successful in applying the integrative negotiation strategy of logrolling than pairs of negotiators of the two other conditions. Further Helmert contrast coding (i.e., 0, 0, +2, -1 , $-1 ; 0,0,0,+1,-1)$ did not reveal any other significant interaction effects, all $F \mathrm{~s}<2.1$.

\section{Discussion}

Experiment 3 replicated the findings of Experiment 2 with respect to negotiated final agreements: whereas prosocial goal intentions only tended to reduce the obstructive effects of a loss-frame, implementation intentions helped to completely overcome the cognitive barrier of a loss-frame. Analyses on the course of the negotiation showed that prosocial implementation intentions did not unfold their effects right away from the start. In fact, at the start of the negotiation only the framing of the negotiation outcomes in terms of losses or gains affected participants' negotiation behavior, whereas the instructions on prosocial goal intentions and corresponding implementation intentions did not yet influence negotiation behavior. ${ }^{2}$ However, as our analyses

\footnotetext{
${ }^{2}$ Statistical analyses on profit points within the first negotiation round only revealed a highly significant main effect of the factor of cognitive frame, $F(1,90)=9.50, p<.01$, whereas all other main or interactions effects were not significant, all $F_{\mathrm{S}}<.5$. Furthermore, there was no significant main or interaction effect for the dependent variable of logrolling in the first negotiation round.
}

on the course of the negotiation indicate, loss-frame pairs of negotiators who had furnished their prosocial goals with corresponding implementation intentions revealed a steeper progress in profit points than loss-frame pairs of negotiators without prosocial if-then plans; actually, at the end of the negotiation they achieved negotiation agreements that were comparable to those of gain-frame pairs of negotiators.

Furthermore, as in Experiment 2, implementation intentions were strongly associated with using the integrative negotiation strategy of logrolling. Apparently, having one's negotiation behavior controlled by implementation intentions saved cognitive resources that could be used to successfully discover integrative solutions. This assumption is also confirmed by the course of negotiation: after the second negotiation round, pairs of negotiators who had formed prosocial implementation intentions more successfully applied the integrative negotiation strategy of logrolling than pairs of negotiators who had not formed prosocial implementation intentions. It appears, then, that implementation intentions saved cognitive resources that could be used in later negotiation rounds to uncover differences in the negotiators' preferences towards the given negotiation issues.

Finally, Experiment 3 also confirmed our assumption that prosocial goals that are furnished with respective implementation intentions only then achieve beneficial effects over and above mere prosocial goals if the negotiation context undermines the negotiators' capability to cooperate (e.g., loss frames that stipulate a high resistance to concession making). As gain-frame negotiation contexts commonly do not increase negotiators resistance to concession making, implementation intentions were not necessary to strengthen the pursuit of prosocial goals. This finding is in line with previous research (summarized by Gollwitzer et al., 2005; Gollwitzer \& Sheeran, 2006) on implementation intentions, in which if-then plans facilitated the pursuit of goals only in situations in which the successful pursuit of desired end-states is endangered by unwanted negative influences that may originate both from outside or inside the person.

\section{General discussion}

In the present studies, cognitive loss frames turned out to be a reliable barrier to social conflict resolution. In the first experiment, mixed-frame negotiators arrived at unfair outcomes favoring the loss-frame negotiation partner. In the second and third experiment, loss-frame pairs of negotiators arrived at lower negotiation outcomes than gain-frame pairs of negotiators. Most importantly, however, in line with our shielding hypothesis the current research suggests that prosocial goals furnished with respective plans are a powerful self-regulation tool to shield prosocial goal pursuit from the resistance to concession making arising from cognitive loss frames, whereas mere prosocial goals are less effective. These differential effects of mere goals versus goals 
that are furnished with plans (i.e., implementation intentions) may account for the observation that prosocial motives sometimes turned out to improve the negotiation performance of loss-frame negotiators compared to gainframe negotiators (Carnevale et al., 1994), weakened it at other times (Olekalns, 1994), or did not make a difference (Olekalns, 1997). Our results thus suggest that trying to ameliorate the negative effects of cognitive loss frames via the setting of mere prosocial goals is rather unreliable, as a significant beneficial effect of prosocial goals is only observed in combination with the self-regulation strategy of forming implementation intentions.

\section{Forming implementation intentions in negotiations}

Negotiation contexts differ from other settings in which implementation intentions have prooved to be a powerful self-regulation tool for goal implementation. The course of negotiations is commonly very hard to predict. As a consequence, suitable situations to act on one's negotiation goals are hard to foresee and it is difficult to quickly select an instrumental goal-directed response in the face of these situations. One way to handle this problem is to link an instrumental goal-directed behavior to a situation (or cue) that one is most likely to encounter in the forthcoming negotiation. As any negotiation requires exchanging proposals, negotiators may select the receiving of a proposal as a distinctive cue to be specified in the if-part of an implementation intention. This situational cue will certainly occur during the negotiation, most likely even repeatedly. Moreover, specifying the receiving of a proposal as the critical cue in an implementation intention should be particularly useful for blocking the effects of loss frames. As receiving a proposal from one's counterpart should make potential losses highly salient and thus activate resistance to concession making, it is this very situation where the finding of fair or integrative agreements is endangered. Being prepared to respond to this critical situation with a prosocial behavior that has been pre-selected in advance guarantees that the person's prosocial goal pursuit does not get derailed.

From a self-regulation research perspective, negotiations lend themselves very well to investigate the effects of selfregulation strategies (e.g., implementation intentions), as negotiations are cognitively highly demanding tasks that involve complex social interactions in which prosocial goal pursuit can easily become derailed. In fact, the present research reveals that the successful pursuit of desired prosocial end-states can easily become derailed by unwanted negative influences such as a resistance to concession making arising from cognitive loss frames. Our findings also contribute to negotiation research within the motivation tradition which revealed that prosocial motives produce inconsistent results in a loss-frame negotiation context (De Dreu et al., 1995; Olekalns, 1994, 1997). The present research adds a self-regulation perspective to this motivation approach by pointing out that forming implementa- tion intentions can be used as a powerful tool when it comes to implementing prosocial goals. Integrating the selfregulation perspective into the field of negotiation research thus contributes to a comprehensive understanding of the essential psychological processes that lead to attaining positive or negative negotiation outcomes.

\section{Implementation intentions and the shielding of prosocial goal pursuits}

As forming implementation intentions did not increase the strength (commitment) of the prosocial goal intention in all three studies conducted, the observed effects of implementation intentions cannot be attributed to changes in the respective goal intention. Further, one might argue that the observed effects of prosocial implementation intentions are due to experimenter demands associated with the respective instructions. However, explaining the findings of the present research in terms of an experimenter demand interpretation seems unwarranted for three reasons: first, instructions to make cooperative counteroffers (Experiment 2) or behaving cooperatively (Experiment 3) did not request from participants to use the cognitive demanding strategy of logrolling. In fact, cooperation instructions may relate to many different types of negotiation behaviors such as exhibiting extensive concessions, making balanced counterproposals, or using the integrative strategy of logrolling. As most inexperienced negotiators falsely assume that their own and their counterparts' preferences are diametrically opposed (fixed pie assumption; Thompson \& Hrebec, 1996), experimenter demand effects should have been reflected in high levels of concession making rather than logrolling. Second, experimenter demand effects should have kicked in right away from the start of the negotiation process in Experiment 3. In contrast, however, analyses on participants' cooperation behavior at the start of the negotiation only revealed an influence of the loss-frame versus gain-frame negotiation context, indicating that loss-frame pairs of negotiators revealed a high resistance to concession making right at the start of the negotiation. Third, experimenter demand effects of the implementation intention instructions should have been observed not only within a loss-frame but also within a gain-frame negotiation context. However, as analyses of Experiment 3 revealed, implementation intention instructions did not affect gain-frame pairs of negotiators behavior. It appears, then, that implementation intentions only unfold their beneficial effects in a loss-frame negotiation context in which negotiators have to overcome their resistance to concession making. Thus, findings of the present research are in line with prior research on implementation intentions which revealed that implementations never increased the level of experimenter demand above the level that was observed for the respective mere goal intentions (Gollwitzer \& Sheeran, 2006).

In the present research, we took much care to specify prosocial goal intentions and respective implementation intentions on the same level of abstraction. Therefore, goal 
intention and implementation intentions instructions only differed in their format. Goal intentions specified a desired behavior (e.g., to be fair, to be cooperative), whereas implementation intention linked that very behavior to an anticipated critical cue (e.g., receiving a counteroffer). Consequently, the observed differences between goal intention an implementation intention participants can hardly be explained by differences in the concreteness of the specified desired behaviors.

As the goals and plans in the present research were assigned rather than self-set, one might wonder whether self-set goals and plans are even more productive in achieving desired effects. However, as Locke and Latham (1990) suggest, it is not self-set versus assigned that makes a difference, but the person's commitment to the goal at hand. As the manipulation checks of the present studies revealed, our research participants felt highly committed to the assigned prosocial goals and plans.

\section{Loss-Frame and gain-frame manipulation}

Our manipulation of a loss-frame versus gain-frame negotiation task reveals some similarities to the experimental manipulations used in studies on the endowment effect (Thaler, 1980, 1985). Research on the endowment effect has shown repeatedly that people demand a higher price for issues they already hold in possession as compared to issues they do not own yet. One widely accepted explanation for this effect is based on prospect theory (Kahneman \& Tversky, 1979) suggesting that "losses loom larger than gains". This concept has later been referred to as loss-aversion or resistance to concession making (Kahneman, 1992; Kahneman, Knetsch, \& Thaler, 1991). Indeed, in a recent classification of different manipulations of framing effects, Levin, Schneider, and Gaeth (1998) referred to the manipulations used in experiments on the endowment effect as goal framing. They point out that this manipulation should be particularly useful to stipulate a high level of loss aversion. Although in the present research all participants were clearly informed that at the outset neither of the negotiation parties already possessed the given issues (i.e., regions, shares) and that negotiation parties were not to gain (gainframe condition) or lose (loss-frame condition) points for issues where they failed to settle ownership, the behavioral component of our manipulation within the first two experiments (to remove or to add flags) included features that are similar to the manipulations used in experiments on the endowment effect. This may have been one reason for the successful manipulation of a strong resistance to concession making (loss aversion) in loss-frame negotiators as compared to gain-frame negotiators in the present research.

\section{Limitations of the current findings}

In the present research, we analyzed prosocial goals and the effects of furnishing such goals with implementation intentions. With this choice of prosocial goals, we do not mean to imply that the attainment of information processing goals (i.e., epistemic goals) cannot be facilitated by forming implementation intentions. Future research may even want to analyze whether implementation intentions are also beneficial to people who operate on the basis of different social and epistemic goal configurations: prosocial thinkers, prosocial misers, egoistic thinkers, and egoistic misers (De Dreu \& Carnevale, 2003).

Also, the present experiments only analyzed negotiations in which both negotiation partners were striving for the same type of goal. Therefore, the present research leaves open what will happen if only one negotiation partner strives for a prosocial goal, whereas the other does not have such a goal or even strives for an egoistic goal. Most importantly, the present research also suggests that implementation intentions will not always unfold their beneficial effects irrespective of the given negotiation context. In fact, prosocial implementation intentions turned out to be a powerful self-regulation tool only within a loss-frame negotiation context, whereas in a gain-frame negotiation context no such effects were observed (Experiment 3). Previous research on implementation intentions suggests that if-then plans only facilitate goal attainment under adverse conditions (summary by Gollwitzer \& Sheeran, 2006). As gainframe negotiation contexts do not undermine negotiators' capability to cooperate with their negotiation partners, implementation intentions are not necessary to shield the pursuit of prosocial goals. Thus, implementation intentions proof to be powerful self-regulation strategies only when the successful pursuit of desired end-states is endangered by unwanted, negative influences.

\section{Conclusion}

The present studies extend the analysis of the self-regulation strategy of forming implementation intentions to complex social interactions implicated in negotiations. Implementation intentions turned out to facilitate the pursuit of prosocial goals in the face of adversity (i.e., loss frames). The present studies add a self-regulation perspective to the motivational research tradition on negotiations by pointing out that the effects of negotiation goals can be enhanced by furnishing them with respective plans (i.e., implementation intentions). Furthermore, the present research revealed that implementation intentions can facilitate goal pursuit in complex social interaction situations that are cognitively very demanding.

\section{References}

Baron, R. M., \& Kenny, D. A. (1986). The moderator-mediator variable distinction in social psychological research: conceptual, strategic, and statistical considerations. Journal of Personality and Social Psychology, 51, 1173-1182.

Bayer, U. C., Moskowitz, G. B., \& Gollwitzer, P. M. (2003). Implementation intentions and action initiation without conscious intent. Unpublished manuscript, University of Konstanz, Germany. 
Bazerman, M. H., Curhan, J. R., Moore, D. A., \& Valley, K. L. (2000) Negotiation. Annual Review of Psychology, 51, 279-314.

Bazerman, M. H., Magliozzi, T., \& Neale, M. A. (1985). Integrative bargaining in a competitive market. Organizational Behavior and Human Decision Processes, 35, 294-313.

Bottom, W. P., \& Studt, A. (1993). Framing effects and the distributive aspect of integrative bargaining. Organizational Behavior and Human Decision Processes, 56, 459-474.

Brandstätter, V., Lengfelder, A., \& Gollwitzer, P. M. (2001). Implementation intentions and efficient action initiation. Journal of Personality and Social Psychology, 81, 946-960.

Carnevale, P. J. D., De Dreu, C. K. W., Rand, K., Keenan, P., \& Gentile, S (1994). Frames in bilateral negotiation: loss aversion versus risk attitude. Unpublished manuscript. University of Illinois at Urbana-Champaign.

De Cremer, D., \& Van Lange, A. M. V. (2001). Why prosocials exhibit greater cooperation than proselfs: the roles of social responsibility and reciprocity. European Journal of Personality, 15, 5-18.

De Dreu, C. K. W. (1996). Gain-loss-frame in outcome-interdependence: Does it influence equality or equity considerations? European Journal of Social Psychology, 26, 315-324.

De Dreu, C. K. W., \& Boles, T. L. (1998). Share and share alike or winner take all? The influence of social value orientation upon choice and recall of negotiation heuristics. Organizational Behavior and Human Decision Processes, 76, 253-276.

De Dreu, C. K. W., \& Carnevale, P. J. D. (2003). Motivational basis of information processing and strategy in conflict and negotiation. Advances in Experimental Social Psychology, 35, 235-291.

De Dreu, C. K. W., Carnevale, P. J. D., Emans, B. J. M., \& Van de Vliert, E. (1994). Effects of gain loss frames in negotiation: loss aversion, mismatching, and frame adoption. Organizational Behavior and Human Decision Processes, 60, 90-107.

De Dreu, C. K. W., Carnevale, P. J. D., Emans, B. J. M., \& Van de Vliert, E. (1995). Outcome frames in bilateral negotiation: resistance to concession making and frame adoption. European Review of Social Psychology, 6, 97-125.

De Dreu, C. K. W., \& Van Lange, P. A. M. (1995). The impact of social value orientations on negotiator cognition and behavior. Personality and Social Psychology Bulletin, 21, 1178-1188.

De Dreu, C. K. W., Weingart, L. R., \& Kwon, S. (2000). Influence of social motives on integrative negotiation: a meta-analytic review and test of two theories. Journal of Personality and Social Psychology, 78, 889-905.

Deutsch, M. (1973). The resolution of conflict: Constructive and destructive decision processes. New Haven, CT: Yale University Press.

Giebels, E., De Dreu, C. K. W., \& Van de Vliert, E. (2000). Interdependence in negotiation: effect of exit options and social motive on distributive and integrative negotiation. European Journal of Social Psychology, 30, 255-272.

Gollwitzer, P. M. (1990). Action-phases and mind sets. In E. T. Higgins \& R. M. Sorrention (Eds.), Handbook of motivation and cognition (Vol. 2, pp. 53-92). New York: Guilford.

Gollwitzer, P. M. (1993). Goal achievement: the role of intentions. European Review of Social Psychology, 4, 141-185.

Gollwitzer, P. M. (1996). The volitional benefits of planning. In P. M. Gollwitzer \& J. A. Bargh (Eds.), The psychology of action: Linking cognition and motivation to behavior (pp. 287-312). New York: Guilford.

Gollwitzer, P. M. (1999). Implementation intentions. Strong effects of simple plans. American Psychologist, 54, 493-503.

Gollwitzer, P. M., \& Brandstätter, V. (1997). Implementation intentions and effective goal pursuit. Journal of Personality and Social Psychology, 73, 186-199.

Gollwitzer, P. M., Bayer, U. C., \& McCulloch, K. C. (2005). The control of the unwanted. In R. Hassin, J. Uleman, \& J. A. Bargh (Eds.), The new unconscious (pp. 485-515). Oxford: Oxford University Press.

Gollwitzer, P. M., \& Moskowitz, G. B. (1996). Goal effects on action and cognition. In E. T. Higgins \& A. T. Kruglanski (Eds.), Social psychology: Handbook of basic principles (pp. 361-399). New York: Guilford.
Gollwitzer, P. M., \& Schaal, B. (1998). Metacognition in action: the importance of implementation intentions. Personality and Social Psychology Review, 2, 124-136.

Gollwitzer, P. M., \& Sheeran, P. (2006). Implementation intentions and goal achievement: a meta-analysis of effects and processes. Advances in Experimental Social Psychology, 36, 69-119.

Guth, W., Schmittberger, R., \& Schwarze, B. (1982). An experimental analysis of ultimum bargaining. Journal of Economic Behavior and Organization, 3, 367-388.

Kahneman, D. (1992). Reference points, anchors, norms, and mixed feelings. Organizational Behavior and Human Decision Processes, 51, 296-312.

Kahneman, D., Knetsch, J. L., \& Thaler, R. (1991). The endowment effect, loss aversion, and status quo bias. Journal of Economic Perspectives, 5, 193-206.

Kahneman, D., \& Tversky, A. (1979). Prospect theory: an analysis of decision under risk. Econometrica, 47, 263-291.

Keppel, G. (1991). Design and analysis: A researcher's handbook (3rd ed.). Englewood Cliffs, NJ: Prentice Hall.

Lengfelder, A., \& Gollwitzer, P. M. (2001). Reflective and reflexive action control in patients with frontal brain lesions. Neuropsychology, 15, 80-100.

Levin, I. P., Schneider, S. L., \& Gaeth, G. J. (1998). All frames are not created equal: a typology and critical analysis of framing effects. Organizational Behavior and Human Decision Processes, 76, 149-188.

Locke, E. A., \& Latham, G. P. (1990). A theory of goal setting and task performance. Englewood Cliffs, NJ: Prentice-Hall.

Messick, D. M., \& McClintock, C. G. (1968). Motivational bases of choice in experimental games. Journal of Experimental Social Psychology, 4, 1-25.

Mischel, W., Cantor, N., \& Feldmann, S. (1996). Principles of self-regulation: The nature of will-power and self-control. In E. T. Higgins \& A W. Kruglanski (Eds.), Social psychology: Handbook of basic principles (pp. 329-360). New York: Guilford

Neale, M. A., \& Bazerman, M. H. (1985). The effects of framing and negotiator overconfidence on bargaining behaviors and outcomes. Academy of Management Journal, 28, 34 49.

Oettingen, G., Hönig, G., \& Gollwitzer, P. M. (2000). Effective self-regulation of goal attainment. International Journal of Educational Research, 33, 705-732.

Olekalns, M. (1994). Context, issues and frame as determinants of negotiated outcomes. British Journal of Social Psychology, 33, 197-210.

Olekalns, M. (1997). Situational cues as moderators of the frame-outcome relationship. British Journal of Social Psychology, 36, 191-209.

Olekalns, M., \& Frey, B. F. (1994). Market forces, negotiator frame and transaction outcomes. European Journal of Social Psychology, 24(3), 403-416.

Pillutla, M. M., \& Murnighan, J. K. (1996). Unfairness, anger, and spite: Emotional rejections of ultimatum offers. Organizational Behavior and Human Decision Processes, 68, 208-224.

Pruitt, D. G., \& Carnevale, P. J. D. (1993). Negotiation in social conflict. Buckingham: Open University Press.

Pruitt, D. G., \& Rubin, J. Z. (1986). Social conflict: Escalation, statement and settlement. New York: McGraw-Hill.

Sobel, M. E. (1982). Asymptotic intervals for indirect effects in structura equations models. In S. Leinhart (Ed.), Sociological methodology (pp. 290-312). San Francisco: Jossey-Bass.

Thaler, R. (1980). Toward a positive theory of consumer choice. Journal of Economic Behavior and Organization, 1, 39-60.

Thaler, R. (1985). Mental accounting and consumer choice. Marketing Science, 4, 199-214.

Thompson, L., \& Hrebec, D. (1996). Lose-lose agreements in interdependent decision making. Psychological Bulletin, 120, 396-409.

Van Lange, P. A. M. (1999). The pursuit of joint outcomes and equality in outcomes: an integrative model of social value orientation. Journal of Personality and Social Psychology, 77, 337-349.

Weingart, L. R., Bennett, R., \& Brett, J. (1993). The impact of consideration of issues and motivational orientation on group negotiation processes and outcomes. Journal of Applied Psychology, 78, 504-517. 